\title{
Human amniotic mesenchymal stem cells and their paracrine factors promote wound healing by inhibiting heat stress-induced skin cell apoptosis and enhancing their proliferation through activating PI3K/AKT signaling pathway
}

Jing-Yuan Li ${ }^{1}{ }^{1}$, , Kang-Kang Ren ${ }^{1}$, Wen-Jie Zhang ${ }^{1}$, Ling Xiao ${ }^{1}$, Han-You Wu', Qian-Yu Liu' ${ }^{1}$, Ting Ding ${ }^{1}$, Xiang-Cheng Zhang ${ }^{3}$, Wen-Jia Nie ${ }^{1}$, Yu Ke ${ }^{1}$, Ke-Yu Deng ${ }^{1}$, Quan-Wen Liu ${ }^{1 *}$ and Hong-Bo Xin ${ }^{1,2^{*}}$ (i)

\begin{abstract}
Background: Increasing evidence has shown that mesenchymal stem cells (MSCS) yield a favorable therapeutic benefit for thermal burn skin wounds. Human amniotic MSCs (hAMSCs) derived from amniotic membrane have multilineage differentiation, immunosuppressive, and anti-inflammatory potential which makes them suitable for treating skin wounds. However, the exact effects of hAMSCs on the healing of thermal burn skin wounds and their potential mechanisms are not explored.

Methods: hAMSCs were isolated from amniotic membrane and characterized by RT-PCR, flow cytometry, immunofluorescence, and tumorigenicity test. We assessed the effects of hAMSCs and hAMSC conditional medium (CM) on wound healing in a deep second-degree burn injury model of mice. We then investigated the biological effects of hAMSCs and hAMSC-CM on the apoptosis and proliferation of heat stress-injured human keratinocytes HaCAT and dermal fibroblasts (DFL) both in vivo and in vitro. Next, we explored the underlying mechanisms by assessing PI3K/AKT and GSK3ß/B-catenin signaling pathways in heat injured HaCAT and DFL cells after hAMSCs and hAMSC-CM treatments using PI3K inhibitor LY294002 and $\beta$-catenin inhibitor ICG001. Antibody array assay was used to identify the cytokines secreted by hAMSCs that may activate PI3K/AKT signaling pathway.

(Continued on next page)
\end{abstract}

\footnotetext{
* Correspondence: liuquanwen@ncu.edu.cn; xinhb@ncu.edu.cn

${ }^{1}$ The National Engineering Research Center for Bioengineering Drugs and the Technologies, Institute of Translational Medicine, Nanchang University, No. 1299 Xuefu Road, Honggutan District, Nanchang 330031, People's Republic of China

Full list of author information is available at the end of the article
}

(c) The Author(s). 2019 Open Access This article is distributed under the terms of the Creative Commons Attribution 4.0 International License (http://creativecommons.org/licenses/by/4.0/), which permits unrestricted use, distribution, and reproduction in any medium, provided you give appropriate credit to the original author(s) and the source, provide a link to the Creative Commons license, and indicate if changes were made. The Creative Commons Public Domain Dedication waiver (http://creativecommons.org/publicdomain/zero/1.0/) applies to the data made available in this article, unless otherwise stated. 


\begin{abstract}
(Continued from previous page)
Results: Our results showed that hAMSCs expressed various markers of embryonic stem cells and mesenchymal stem cells and have low immunogenicity and no tumorigenicity. hAMSC and hAMSC-CM transplantation significantly promoted thermal burn wound healing by accelerating re-epithelialization with increased expression of CK19 and PCNA in vivo. hAMSCs and hAMSC-CM markedly inhibited heat stress-induced apoptosis in HaCAT and DFL cells in vitro through activation of PIBK/AKT signaling and promoted their proliferation by activating GSK3 $\beta / \beta$-catenin signaling. Furthermore, we demonstrated that hAMSC-mediated activation of GSK3 $\beta / \beta$-catenin signaling was dependent on PI3K/AKT signaling pathway. Antibody array assay showed that a panel of cytokines including PAI-1, C-GSF, periostin, and TIMP-1 delivered from hAMSCs may contribute to the improvement of the wound healing through activating PI3K/AKT signaling pathway.

Conclusion: Our results demonstrated that hAMSCs and hAMSC-CM efficiently cure heat stress-induced skin injury by inhibiting apoptosis of skin cells and promoting their proliferation through activating PI3K/AKT signaling pathway, suggesting that hAMSCs and hAMSC-CM may provide an alternative therapeutic approach for the treatment of skin injury.
\end{abstract}

Keywords: Human amniotic membrane mesenchymal stem cells, Conditioned medium, Wound healing, PI3K/AKT signaling, Antibody array

\section{Background}

Skin is considered one of the most vital organs in the body due to its important functions such as an outer protective barrier against various external agents and a temperature regulator [1]. The serious consequences of cutaneous wound, both acute and chronic, can be caused by many different factors. Cutaneous wound healing requires wellcoordinated responses of inflammation, cell proliferation, neovascularization, extracellular matrix formation, and reepithelialization $[2,3]$. With a high rate of morbidity and mortality, skin burn is not only difficult to treat, but also poses a major public health burden worldwide [4]. Thermal burns can be caused by dry sources (fire or flame) and wet sources (scalds) and classified based on the depth of burn [5]. Compared to other wounds, thermal burn wounds are characterized by delayed wound healing because of edema, bacterial infection, chronic inflammation and necrosis [6]. Lack of autologous skin sources or immunological rejection of allogeneic skin brings about the dilemma of clinic treatment of thermal burn [7]. Therefore, developing new and effective wound healing therapies, especially for thermal burn wounds, is urgent.

Recently, stem cell therapy, especially using MSCs, has emerged as a promising new and effective therapeutic strategy for accelerating cutaneous wound healing [2], and this protective effect was predominantly mediated by paracrine rather than direct regenerative mechanisms [8]. Numerous studies have shown that MSCs promote cutaneous wound healing by accelerating wound closure $[9,10]$, enhancing angiogenesis $[11,12]$, inhibiting the inflammatory response $[13,14]$, regulating extracellular matrix remodeling $[15,16]$, inhibiting cell apoptosis, and promoting cell proliferation [17]. Meanwhile, MSCs have been studied as one of the more promising therapies for the healing of the thermal burns [7, 18-20]. Recently, human amniotic membrane- derived mesenchymal stem cells (hAMSCs) have been recognized as one of the most promising stem cells in the field of regenerative medicine. The active proliferative potential, low immunogenic profile, anti-inflammatory function [21], and tissue repair ability of hAMSCs can be beneficial to the burn wound healing as well as the severe systemic effects of burn, including hypermetabolic response, inflammation-related diseases, and immunosuppression [22]. Anna et al. have previously found that conditioned medium derived from MSCs could enhance normal skin fibroblast proliferation and migration and promote wound healing in an excisional full-thickness skin murine model [15]. Similarly, MSC-derived exosomes have been proved to contribute to thermal burn wound healing [17]. Therefore, it is suggested that the effect of MSCs on the wound healing was mediated via a paracrine signaling mechanism. However, the exact effects of hAMSCs on the thermal burn wound healing and their potential mechanism are not explored.

In the present study, we isolated hAMSCs from human amniotic membrane and characterized their morphology, phenotypic profiles, pluripotency, tumorigenicity, and growth potency. In vivo, we investigated the role of hAMSCs in thermal burn wound healing using a mouse deep second-degree burn injury model. We found that hAMSC and hAMSC-CM transplantation promoted skin wound healing by enhancing proliferation and inhibiting apoptosis of skin cells in the wound area. In vitro, a transwell co-culture system and hAMSC-CM were used to assess the influences of hAMSC-secreted factors on the apoptosis, proliferation, and migration of heat injury skin cells. The results showed that hAMSCs or hAMSC-CM inhibited heat stress-induced apoptosis in HaCAT and DFL cells and promoted their proliferation through activation of PI3K/AKT signaling pathway with a paracrine manner. In addition, antibody array assay showed that 
hAMSCs could deliver many cytokines including PAI-1, C-GSF, periostin, TIMP-1, uPAR, and so on, which may activate PI3K/AKT signaling pathway.

\section{Materials and methods}

Isolation, culture, and expansion of hAMSCs

Human fetal placentas were obtained from the Department of Obstetrics and Gynecology, The First Affiliated Hospital of Nanchang University. The verbal consent was obtained from all of the volunteers prior to their participation. The research procedure was approved by the ethics committee of The First Affiliated Hospital of Nanchang University. The amnion is a thin, avascular membrane composed of human amniotic epithelial stem cells (hAESCs) and hAMSCs. For isolation of hAMSCs, hAESCs were firstly released from the amniotic membrane as previously described [21]. Then, the amnion was washed three times with HBSS and digested with Collagenase IV $(1 \mathrm{~g} / \mathrm{L}$, Thermo Fisher, Nanchang, China) on a rotator $40 \mathrm{~min}$ at $37^{\circ} \mathrm{C}$. Digestion was terminated by addition of medium containing $10 \% \mathrm{FBS}$; the single-cell suspension was filtered through a $70-\mu \mathrm{m}$ cell strainer (BD Labware, Shanghai, China) and centrifuged at $1000 \mathrm{rpm}$ for $5 \mathrm{~min}$. The supernatant was discarded, and the cells were re-suspended with $\alpha$-MEM medium (Thermo Fisher) containing 18\% Chang B, 2\% Chang C (Irvine Scientific), 10\% FBS, 1\% glutamine, and 1\% penicillin/ streptomycin (Gibco). hAMSCs were placed in cell culture dishes (Corning, NY, USA) at a density of $5 \times 10^{4}$ cells $/ \mathrm{cm}^{2}$ at $37^{\circ} \mathrm{C}$ with $5 \% \quad \mathrm{CO}_{2}$ atmosphere. Unattached cells and debris were removed after 2 days. In each experiment, the cells were grown to approximately $80 \%$ confluence, and only cells between passages 3 and 7 were used for subsequent experiments.

\section{Collection of conditioned medium (CM) of hAMSC}

For the collection of hAMSC-CM, hAMSCs were grown in a normal culture medium. Once the cells reached $80 \%$ confluency, the medium was changed to high-glucose Dulbecco's modified Eagle's medium (H-DMEM, Thermo Fisher) containing $100 \mathrm{U} / \mathrm{ml}$ penicillin/streptomycin. CM was collected after $48 \mathrm{~h}$ and centrifuged at $1500 \mathrm{rpm}$ for $5 \mathrm{~min}$ to ensure complete removal of cellular debris. CM was then concentrated 10-fold by using an Amicon ${ }^{\bullet}$ Ultra $3 \mathrm{~K}$ device (MilliporeSigma, USA).

\section{Reverse transcription-polymerase chain reaction (RT-PCR)}

Total RNA from each sample was extracted by the Trizol reagent (Thermo Fisher). Purity was assessed by the absorbance ratio at 260 and $280 \mathrm{~nm}$. RNA (100 ng to $1 \mu \mathrm{g}$ ) was reverse transcribed into cDNA with the M-MLV Reverse Transcriptase (Promega, Shanghai, China) according to the manufacturer's instructions. The primers for the target products were designed as in Table 1. Polymerase
Table 1 Primers and conditions used for RT-PCR to detect gene transcripts in hAMSCs

\begin{tabular}{|c|c|c|c|}
\hline Genes & Sequence & $\mathrm{TM}\left({ }^{\circ} \mathrm{C}\right)$ & Size $(b p)$ \\
\hline \multirow[t]{2}{*}{ GAPDH } & F:5'-CCACCCATGGCAAATTCCATGGCA-3' & 59 & 598 \\
\hline & R:5'-TCTAGACGGCAGGTCAGGTCCACC-3' & & \\
\hline \multirow[t]{2}{*}{ Nanog } & F:5'-CAATGGTGTGACGCAGGGAT-3' & 52 & 149 \\
\hline & R:5'-TGCACCAGGTCTGAGTGTTC-3' & & \\
\hline \multirow[t]{2}{*}{ OCT4 } & F:5'-ATCCCTGAACCTAGTGGGGA-3' & 59 & 480 \\
\hline & R:5'-CACTCGGACCACATCCTTCT-3' & & \\
\hline \multirow[t]{2}{*}{ CD105 } & F:5'-TCCTCCCAAGGACACTTGTA-3' & 57 & 244 \\
\hline & R:5'-CGCCTCATTGCTGATCATAC-3' & & \\
\hline \multirow[t]{2}{*}{ CD29 } & F:5'-CCGCGCGGAAAAGATGAAT-3' & 55 & 406 \\
\hline & R:5'-AAATGTCTGTGGCTCCCCTG-3' & & \\
\hline \multirow[t]{2}{*}{ CD90 } & F:5'-GAGGGAGGAAGAGCAGACCT-3' & 57 & 896 \\
\hline & R:5'-CCTGGATCGGGTTATGATGGG-3' & & \\
\hline \multirow[t]{2}{*}{ CD34 } & F:5'-GCAAGCCACCAGAGCTATTC-3' & 55 & 390 \\
\hline & R:5'-GGTCCCAGGTCCTGAGCTAT-3' & & \\
\hline \multirow[t]{2}{*}{ CD133 } & F:5'-ATCCTTTCCATTACGGCGGC-3' & 57 & 311 \\
\hline & R:5'-CTCAAGGCACCATCCCGTG-3' & & \\
\hline
\end{tabular}

$F$ Forward primer, $R$ Reverse primer

chain reactions $(\mathrm{PCR})$ were carried out in a PCR thermal cycler (Thermo Hybaid, Waltham, MA, USA). PCR products were electrophoresed on a $1.0 \%(\mathrm{~m} / \mathrm{v})$ agarose gel containing $0.5 \mu \mathrm{g} / \mathrm{ml}$ ethidium bromide for nucleic acid visualization under UV light. In parallel, mRNA levels of human housekeeping GAPDH were analyzed as an internal normalization control.

\section{Identification of hAMSCs by flow cytometry}

Phenotypic analyses of cultured hAMSCs were performed using standard flow cytometry methods. Passage 3 hAMSCs were collected in fluorescence-activated cell sorting (FACS) tubes (BD Biosciences, Franklin Lakes, NJ) at a concentration of $1 \times 10^{6}$ cells $/ \mathrm{ml}$ in stain FACS buffer (PBS containing 2\% FBS) and then stained with FITC-conjugated antibodies against human CD29, CD90, CD45, HLA-DR, CD80, and CD40; phycoerythrin (PE)-conjugated antibodies against human CD73, CD105, CD34, HLA-ABC, and CD86; and their isotype controls (all from BD Biosciences) at $4{ }^{\circ} \mathrm{C}$ for $30 \mathrm{~min}$ in the dark. After washing twice, the cells were resuspended in $200 \mu \mathrm{l}$ of PBS and acquired by a FACSCalibur instrument (BD Biosciences). Data were analyzed using FLOWJO TM software (TreeStar, Inc., Ashland, OR, USA).

\section{Immunofluorescence}

Immunofluorescence experiments were carried out following our previously reported protocols [21]. Briefly, cells growing on the glass slide were fixed with $4 \%$ paraformaldehyde for $15 \mathrm{~min}$ and permeabilized using $0.25 \%$ 
Triton X-100 diluted in PBS for $10 \mathrm{~min}$ at room temperature. To block unspecific epitopes, cells were incubated with PBS containing 1\% BSA and 0.1\% Tween-20 for $1 \mathrm{~h}$. Cells were then incubated with the following primary antibodies at $4{ }^{\circ} \mathrm{C}$ overnight: rabbit anti-OCT4 (5 $\mu \mathrm{g} / \mathrm{ml}$, Abcam, Nanchang, China), mouse anti-SSEA-4 $(15 \mu \mathrm{g} / \mathrm{ml}$, Abcam), rabbit anti-Nanog (1:200, Abcam), rabbit anti-Ki67 (1:100, Abcam), and mouse anti-PCNA $(5 \mu \mathrm{g} / \mathrm{ml}$, Abcam). After that, cells were incubated with secondary donkey anti-mouse or anti-rabbit antibodies conjugated to either Alexa Fluor 488 or Alexa Fluor 568 (Jackson, Nanchang, China). Nuclei were counterstained with DAPI (Thermo Fisher).

\section{Adipogenic and osteogenic differentiation}

Passage 3 hAMSCs were seeded at a density of $1.5 \times 10^{5}$ cells/well in a six-well plate. When the cells reached $100 \%$ confluence, OriCell ${ }^{\mathrm{TM}}$ human mesenchymal stem cell adipogenic differentiation medium (Cyagen Biosciences, Shanghai, China) was added to wells according to the manufacturer's instruction. After 24 days of induction, Oil red O (Cyagen Biosciences) staining was performed to assess the differentiation potential of adipogenesis formation of intracellular lipid droplets. For osteogenic differentiation, hAMSCs were cultured with OriCell ${ }^{\mathrm{ms}}$ human mesenchymal stem cell osteogenic differentiation medium (Cyagen Biosciences) for 23 days to analyze the osteogenic differentiation. The differentiation potential for osteogenesis was assessed by Alizarin Red (pH 4.2, 40 mM) (Cyagen Biosciences) staining.

\section{Soft agar tumorigenicity test}

Each well of the 6-well culture plates was first coated with $0.6 \%$ soft agar (bottom layer). A $0.3 \%$ soft agar containing hAMSC $_{\mathrm{S}}\left(1 \times 10^{3} /\right.$ well $)$ was then layered on top of the $0.6 \%$ gel and incubated at $37^{\circ} \mathrm{C}$ with $5 \% \mathrm{CO}_{2}$ for 30 days. Human liver carcinoma cell HepG2 was used as the control. Colony formation was observed and imaged by phase-contrast microscopy.

\section{In vivo tumorigenicity test}

To test the tumorigenicity of hAMSC $\mathrm{S}_{\mathrm{S}}$ in vivo, $5 \times 10^{6}$ hAMSCs (in $200 \mu \mathrm{l}$ PBS) were injected into the left thigh muscle and the right back of NOD-SCID mice, respectively. The same number of embryonic stem cells was used as positive control. The tumor-forming was monitored every day for up to 20 weeks.

\section{In vivo skin wound model and treatment}

Adult male C57BL/6 mice (8 weeks old) were purchased from Changsha SLAC Laboratory Animal Company (Changsha, China, http://www.hnsja.com/) and housed under standard laboratory conditions with standard chow and water daily at the Laboratory Animal Center of Institute of Translational Medicine of Nanchang
University. All animal procedures described here were reviewed and approved by the Animal Care and Use Committee of Nanchang University. Mice were anesthetized, and back cutaneous hair was removed by electrical shaving. The back skin of mice was injured with $80^{\circ} \mathrm{C}$ water for $100 \mathrm{~s}$ to create a $10-\mathrm{mm}$ diameter wound. Meanwhile, $200 \mu \mathrm{l} \mathrm{PBS,} 2 \times 10^{6}$ hAMSCs suspended in $200 \mu \mathrm{l} \mathrm{PBS}, 200 \mu \mathrm{l} \mathrm{H}$-DMEM (10X), or $200 \mu \mathrm{l} \mathrm{hAMSC-}$ CM (10X) were injected subcutaneously near the wound at four sites. The normal group had no treatment.

\section{Whole-body fluorescent imaging}

For the purpose of cell tracking, hAMSCs were labeled with PKH26 red fluorescent dye (Sigma-Aldrich) and then injected subcutaneously near the wound at four sites. Mice were anesthetized after 0 days, 7 days, 14 days, and 21 days of cell injection and visualized with whole-body fluorescent imaging system (LB983; Berthold, Germany).

\section{Histopathology and TUNEL assay}

Skin tissue samples of all groups were excised and fixed in $4 \%$ paraformaldehyde, embedded in paraffin, sectioned at $5-\mu \mathrm{m}$ thickness, and mounted on slides. The slides were deparaffinized and stained with hematoxylin and eosin (H\&E), PCNA (1:1000, mouse monoclonal, Abcam), CK19 (1:1000, mouse monoclonal, Abcam), Anti-Human Nuclei Antibody MAB1231 (1:200, mouse monoclonal, Merck), CD90 (1:250, rabbit monoclonal, Abcam), and CD31 (1:100, mouse monoclonal, Abcam).

Apoptosis was analyzed on paraffinic skin tissue sections of different group by TUNEL assay kit (Millipore, USA). Three sections were selected for each mouse and stained using the TUNEL assay kit following the manufacturer's protocol.

\section{Western blot analysis}

Total protein was extracted from HaCAT cells, DFL cells, and skin tissues. Western blot was performed to detect the target proteins. Sixty micrograms of total protein was run on $10 \%$ denaturing SDS-PAGE gels, then transferred to nitrocellulose membranes (BioRad), which were incubated with primary antibodies anti-GAPDH (1:1000, rabbit monoclonal, Santa Cruz), anti- $\beta$-actin (1:1000, mouse polyclonal, CST), anti-Bcl-2 (1:1000, mouse monoclonal, Abcam), anti-Bax (1:1000, mouse monoclonal, Abcam), anti-PCNA (1:1000, mouse monoclonal, Abcam), antiCK19 (1:1000, mouse monoclonal, Abcam), PI3K (1:1000, rabbit polyclonal, CST), P-PI3K (1:1000, rabbit polyclonal, CST), anti-AKT (1:1000, mouse monoclonal, Abcam), antiP-AKT (1:1000, mouse monoclonal, Abcam), mTOR (1: 1000, rabbit polyclonal, CST), P-mTOR (1:1000, rabbit polyclonal, CST), anti- $\beta$-Catenin (1:1000, mouse monoclonal, Abcam), anti-GSK3 $\beta$ (1:1000, mouse monoclonal, Abcam), and anti-P-GSK3 $\beta$ (1:1000, mouse monoclonal, 
Abcam) at $4{ }^{\circ} \mathrm{C}$ overnight. Blots were detected with horseradish peroxidase (HRP)-conjugated goat anti-rabbit or rabbit anti-mouse secondary antibody (Invitrogen) for $1 \mathrm{~h}$ at room temperature. Images were quantified using the Super Signal West Pico or Femto chemiluminescent detection system (Pierce).

\section{Tube formation assay}

Human umbilical vein endothelial cells (HUVECs) were obtained from ATCC and cultured following the manufacturer's instructions. Matrigel Basement Membrane Matrix (BD Biosciences, CA, USA) was added in 48-well plates $\left(130 \mu \mathrm{l}\right.$ per well) and solidified at $37^{\circ} \mathrm{C}$ for $1 \mathrm{~h}$. Then, $2.0 \times 10^{4}$ HUVECs per well were seeded and cultured with normal medium or normal medium supplemented with $10 \%$ hAMSC-CM (10X). After incubating at $37^{\circ} \mathrm{C}$ and $5 \% \mathrm{CO} 2$ for $2 \mathrm{~h}, 4 \mathrm{~h}$, and $6 \mathrm{~h}$, the tube formation was detected under a microscope.

\section{In vitro co-culture experiment}

Keratinocytes HaCAT cells were purchased from ATCC and cultured in H-DMEM supplemented with 15\% FBS and $1 \%$ penicillin/streptomycin (all from Thermo Fisher) at $37^{\circ} \mathrm{C}$ in a $5 \% \mathrm{CO}_{2}$ humidified atmosphere. DFL were isolated from discarded circumcised foreskin on healthy boys as previously described $[23,24]$ and cultured in $\mathrm{H}$ DMEM containing 15\% FBS and 1\% penicillin/streptomycin at $37{ }^{\circ} \mathrm{C}$ with $5 \% \mathrm{CO}_{2}$. DFL cells between passages 3 to 5 were used for subsequent experiments.

Skin cells (HaCAT and DFL) were trypsinized and seeded in a 6 -well dish at $1.5 \times 10^{5}$ cells/well. To mimic the burn injury model in vivo, cells were treated at $43^{\circ} \mathrm{C}$ for $50 \mathrm{~min}$ in a water bath. For the normal medium (NM) group, cells were incubated with $3 \mathrm{ml} \mathrm{H}$-DMEM containing 15\% FBS and 1\% penicillin/streptomycin. For hAMSCs group, a co-culture transwell chamber $(2.4-\mathrm{cm}$ diameter, 0.4- $\mu \mathrm{m}$ pore size; Corning) was used to assess the effects of hAMSCs on heat stress-injured skin cells in vitro. Skin cells were seeded into the lower chamber in $2.0 \mathrm{ml}$ of $\mathrm{H}$-DMEM with 15\% FBS, and hAMSCs were seeded in the upper compartment at a 1:1 ratio with skin cells in $1.0 \mathrm{ml}$ of the same medium. For the hAMSC-CM group, cells were cultured with $3 \mathrm{ml} \mathrm{H-DMEM}$ supplemented with $10 \%$ hAMSC-CM (10X), 15\% FBS, and 1\% penicillin/streptomycin. Skin cells cultured in the normal medium not treated at $43{ }^{\circ} \mathrm{C}$ for 50 min were used as the control group. Samples were collected after culturing for 24 and $48 \mathrm{~h}$.

\section{In vitro skin cells proliferation and apoptosis analysis}

Cell proliferation was evaluated at indicated time points using the CCK- 8 kit (Dojindo Laboratories, Kumamoto, Japan), following the manufacturer's protocol. CCK-8 reagent (10\%) was added to each well for $3 \mathrm{~h}$ at $37^{\circ} \mathrm{C}$.
Viability was evaluated by measuring the absorbance at a 450-nm wavelength with using a microplate spectrophotometer (BioRad).

For the apoptosis assays, $1.0 \times 10^{5}$ cells were collected from each sample and resuspended in $100 \mu \mathrm{l}$ Annexin V binding solution containing $5 \mu \mathrm{l}$ Annexin V-FITC and $5 \mu \mathrm{l}$ propidium iodide (PI) solution (Dojindo). After incubation for $15 \mathrm{~min}$ at room temperature, cells were washed in PBS, centrifuged at $1000 \mathrm{rpm}$ for $5 \mathrm{~min}$, and resuspended in $400 \mu \mathrm{l}$ Annexin V Binding Buffer. The apoptosis assays were run and analyzed with BD Jazz.

\section{In vitro scratch-wound-closure assay}

$\mathrm{HaCAT}$ and DFL cells were seeded into 6-well dishes at a density of $1.5 \times 10^{5}$ cells per well. When the cells reached $100 \%$ confluency, the monolayers were scratched using a sterile $200 \mu \mathrm{l}$ pipette tip. After disruption, monolayers were gently washed twice with PBS to remove cell debris. Subsequently, the cells were treated with PBS, hAMSCs, or hMBSC-CM. The dishes were incubated at $37^{\circ} \mathrm{C}$ in a $5 \% \mathrm{CO}_{2}$ air atmosphere for $48 \mathrm{~h}$. Images were acquired at 48-h time points, and the migration area of $\mathrm{HaCAT}$ and DFL cells were measured by using Image Pro Plus 6.0 software.

\section{Cytokine antibody array}

We collected 3 hAMSC-CM samples; the profiles of cytokines secreted by hAMSCs were detected in the culture supernatants using a Human Cytokine Array (RayBiotech, Guangzhou, China) according to the manufacturer's instructions.

\section{Statistical analysis}

The results are presented as average value \pm standard deviation (SD). Student's $t$ test was used for analysis between two groups. One-way analysis of variance (ANOVA) was used to compare data among three or more groups. Differences with a $P$ value of $<0.05$ were considered statistically significant.

\section{Results}

\section{Identification and characterization of hAMSCs}

Cultured primary and passaged hAMSCs formed a monolayer of adherent cells and exhibited a spindle-shaped, fibroblast-like morphology. In the presence of bFGF (10 $\mathrm{ng} / \mathrm{ml}$ ), the hAMSCs were proliferated robustly and the average doubling time was 2 days (Fig. 1a). hAMSCs were positive for mesenchymal stem cell markers CD29, CD73, CD105, and CD90 and negative for hematopoietic stem cell markers CD133, CD34, and CD45 as determined by RT-PCR and flow cytometry (Fig. 1b, c). hAMSCs also expressed the major histocompatibility protein HLA-ABC but none of its co-stimulatory molecules CD80, CD86, and CD40, nor major histocompatibility protein HLA-DR 

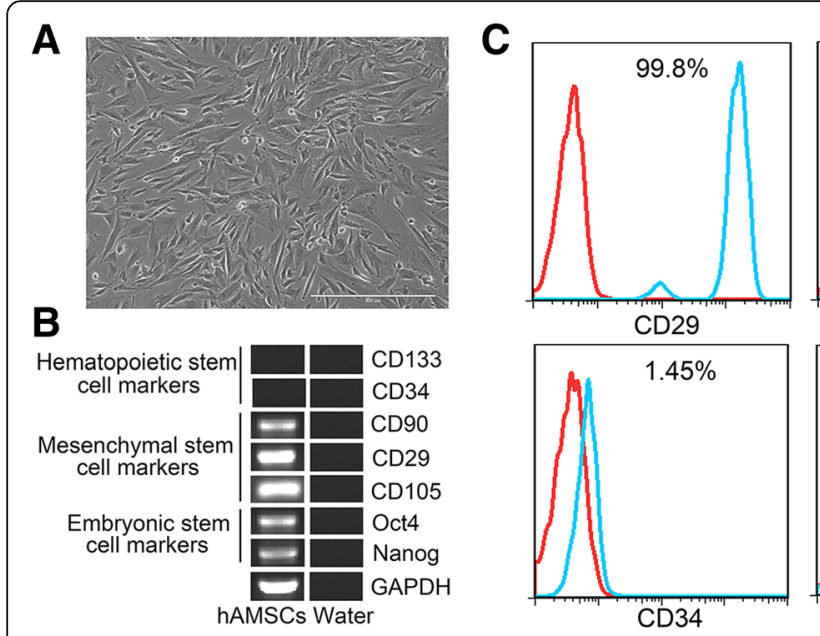

E
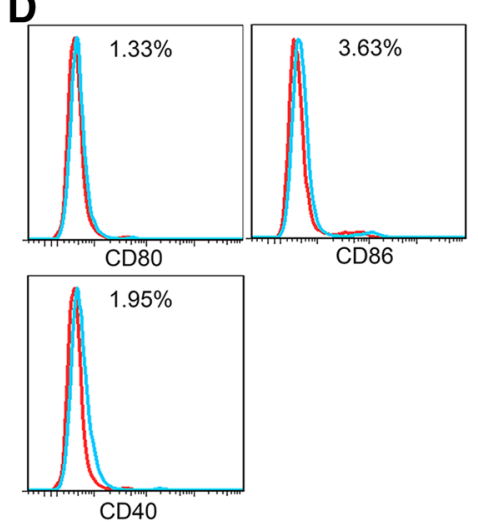

CD29
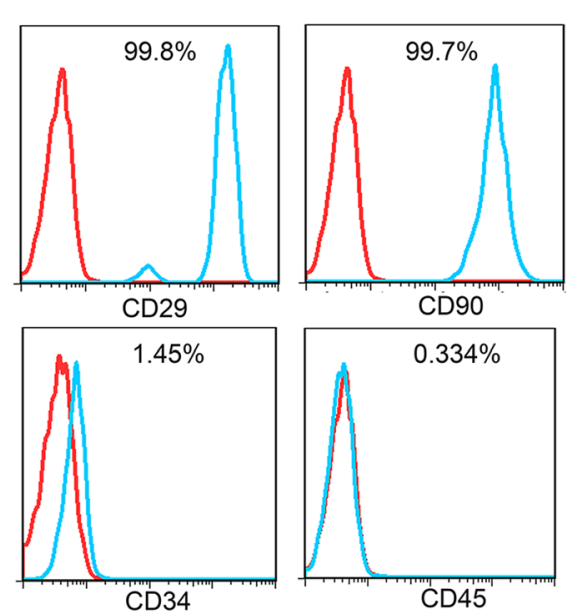

CD 90

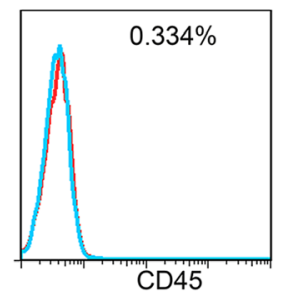

$\mathrm{CD} 45$

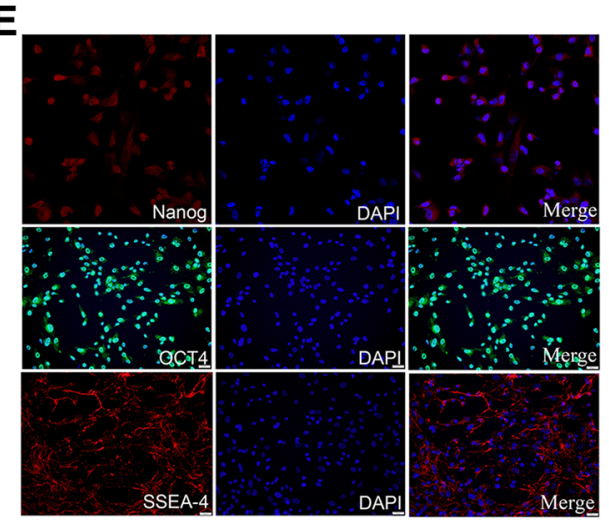

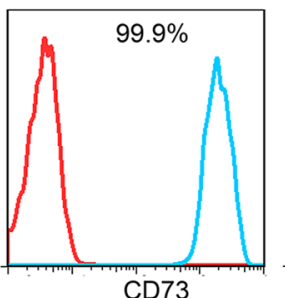

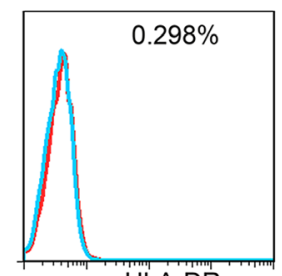

HLA-DR

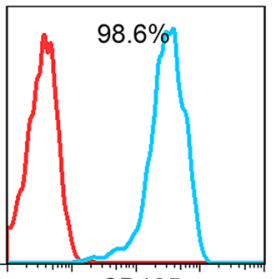

CD105

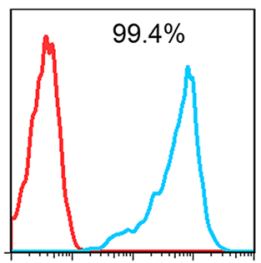

HLA-ABC $F$

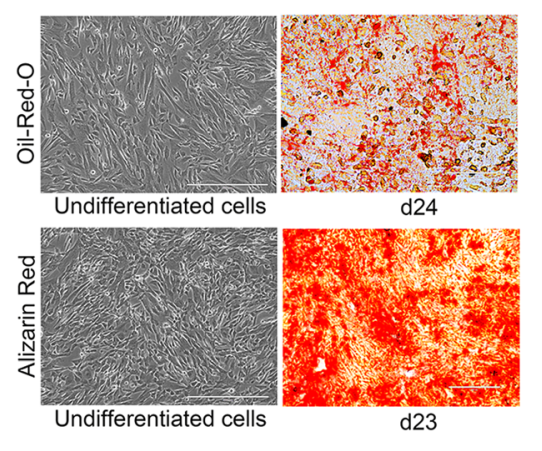

Fig. 1 Identification of hAMSCs. a Representative photomicrograph of adherent hAMSCs with spindle shapes on plastic cell culture dish. b RTPCR analysis for the expressions of markers in hAMSCs. hAMSCs specifically expressed various markers of Nanog, Oct4, CD105, CD29, and CD90, but not CD34 and CD133. Water was used as negative control. c Flow cytometry analysis of CD29, CD90, CD73, CD105, CD34, CD45, HLA-DR, and HLA-ABC expression in hAMSCs. The red lines represent the isotype control, and the blue lines represent the level of surface markers. $\mathbf{d}$ The hAMSCs were negative for HLA-ABC co-stimulatory molecules CD80, CD86, and CD40. e Immunofluorescence staining of the embryonic stem cell surface markers Oct4, SSEA-4, and Nanog in hAMSCs. f Multiple differentiation potential of hAMSCs. The hAMSCs were differentiated into matured adipocytes and osteocytes after incubation with adipogenic or osteogenic differentiation medium at the times indicated, respectively. Adipocytes and osteocytes differentiated from hAMSCs were determined by staining with Oil Red O and Alizarin Red, respectively

(Fig. 1c, d), indicating that these cells possess low immunogenicity. The expressions of embryonic stem cell surface markers Nanog, Oct4, and SSEA-4 were also analyzed by RT-PCR and immunofluorescence. The results showed that hAMSCs expressed all of these pluripotent markers (Fig. 1b, e), indicating that hAMSCs have the capacity of self-renew as well as multi-lineage differentiation potentials. To identify the multipotency of hAMSCs, we performed adipogenic and osteogenic differentiation assays. Under adipogenic and osteogenic differentiation conditions, most hAMSCs could differentiate into adipocytes and osteocytes, respectively (Fig. 1f).

Soft agar colony formation assay provides an ideal tool for identifying the tumorigenicity of hAMSCs in vitro. After 30 days of cell growth in the soft agar, many colonies were visible in Hepg2 group but no colony was observed in the hAMSCs group at the same time (Additional file 1:
Figure S1A). In addition, we injected the hAMSCs and embryonic stem cells (positive control) into the left thigh muscle and right back of NOD-SCID mice. The results showed that large tumors were formed in all mice implanted with embryonic stem cells within 8 weeks $(n=5)$. In contrast, no tumor formation in any of the hAMSC-injected animals over a time period of 20 weeks (Additional file 1: Figure S1B).

\section{hAMSC and hAMSC-CM transplantation accelerates skin wound healing in a mouse model}

To examine the therapeutic potential of hAMSCs and hAMSC-CM on wound healing, we established a mouse deep second-degree burn injury model and injected $200 \mu \mathrm{l}$ PBS containing $2 \times 10^{6}$ hAMSCs, or $200 \mu \mathrm{l}$ concentrated hAMSC-CM to heat-injured wounds created in C57BL/6 mice. Similar wounds treated with PBS or 
H-DMEM were used as controls. The wounds at 7 days, 14 days, and 21 days were carefully measured, showing that hAMSCs and hAMSC-CM significantly accelerated wound closure compared to PBS and H-DMEM (Fig. 2a, b). For cell-tracking purposes, hAMSCs were labeled with PKH26. Mice were anesthetized after 0 days, 7 days, 14 days, and 21 days of cell injection and visualized with a whole-body fluorescent imaging system. As shown in Fig. 2c, hAMSCs
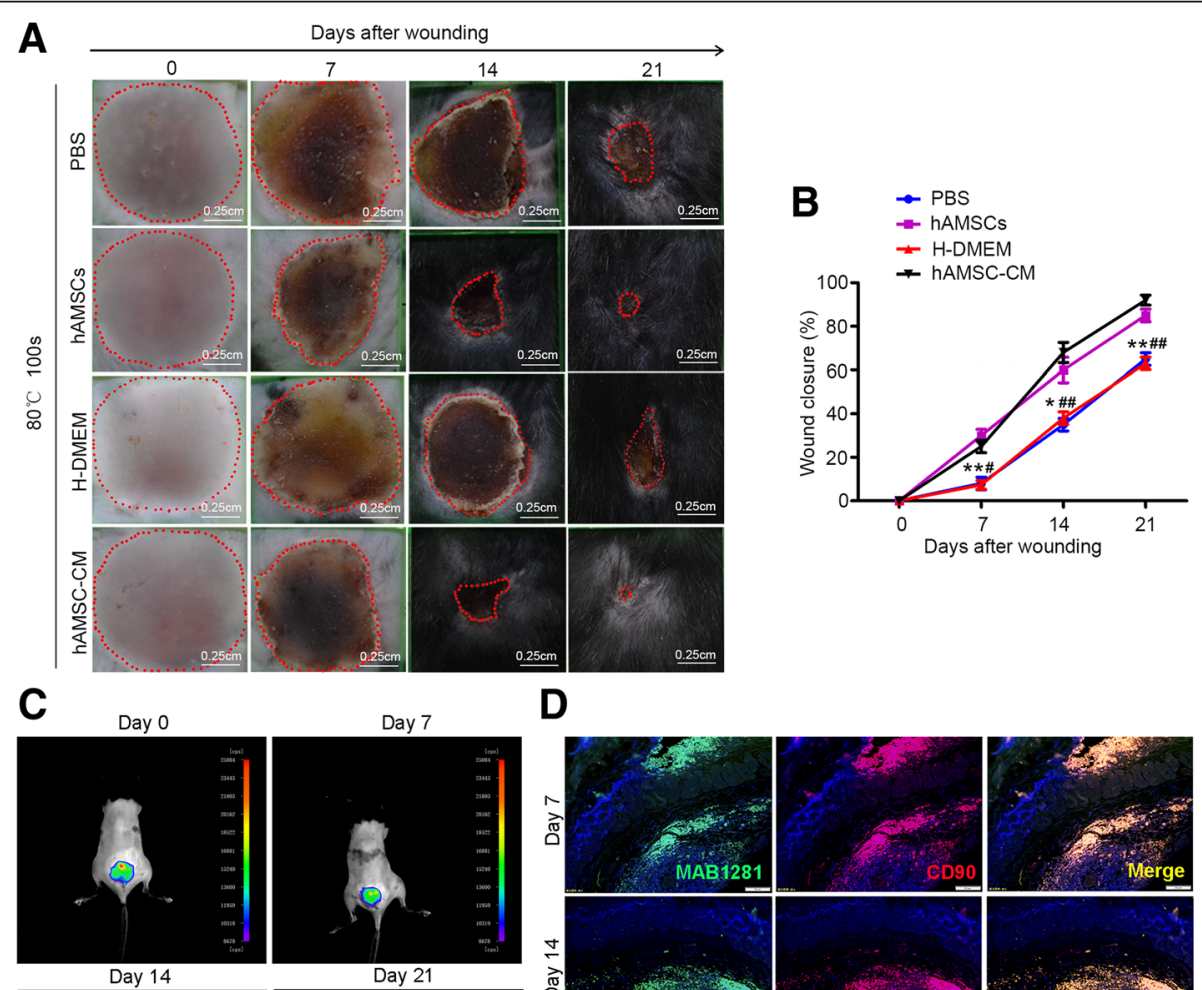

D
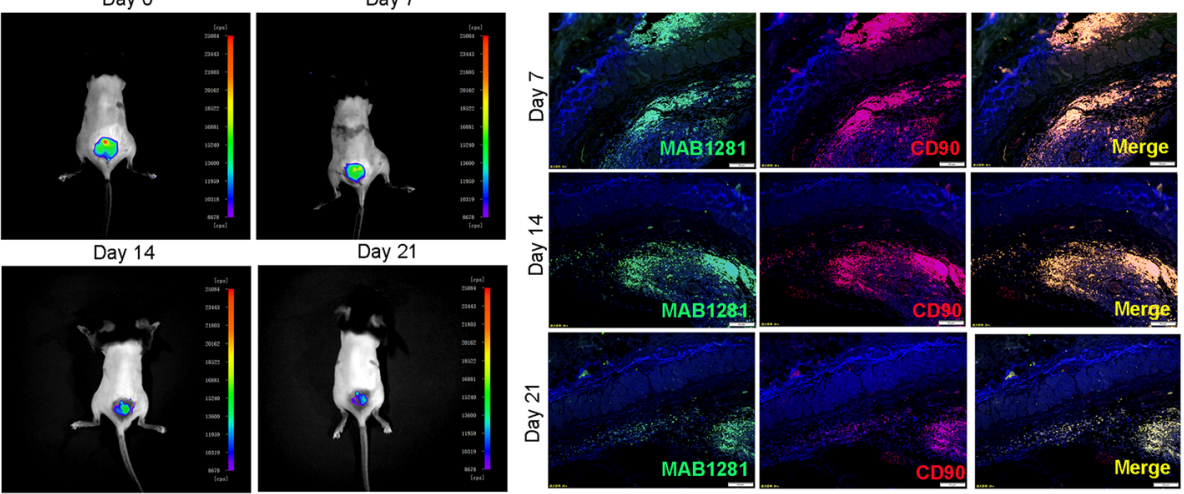

E
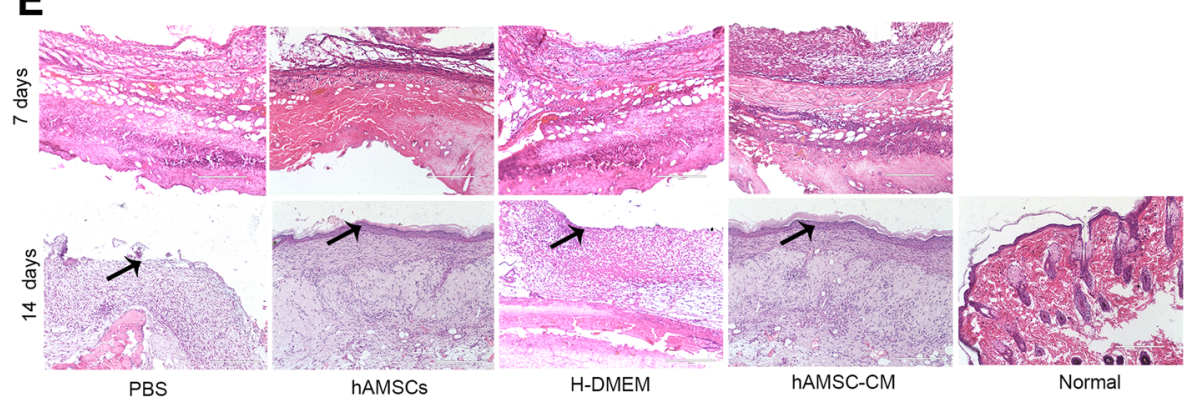

Fig. 2 hAMSCS or hAMSC-CM accelerated wound closure by subcutaneously injected around the injured site in C57BL/6 mice. a Representative images of wounds after transplantations of PBS, hAMSCs, H-DMEM, and hAMSC-CM at day 0, day 7, day 14, and day 21. b Measurement of wound closure at different time points treated with PBS, hAMSCS, H-DMEM, or hAMSC-CM. The results showed that the wound closure was significantly increased in response to hAMSCs and hAMSC-CM $(n=5)$. The percentage of wound closure was calculated as (area of original wound - area of measured wound)/area of original wound $\times 100$. *PBS group compared with hAMSCs group; \#H-DMEM group compared with the hAMSC-CM group. $\mathbf{c}$ Whole-body fluorescent imaging analysis of PKH26-labeling in hAMSCs in vivo at day 0, day 7, day 14, and day 21. d Immunofluorescence images of the sections from day-7, day-14, and day-21 skin tissues in PKH26-labeled hAMSCs. hAMSCs were co-stained with MAB1281 (antibody to human-specific nuclei) and CD90 and imaged by confocal microscope. e Representative photomicrographs of H\&E stained sections from day-7 and day-14 wounds injected with PBS, hAMSCS, H-DMEM, or hAMSC-CM. The arrows indicate the layers of keratinocytes. Normal skin was used as a control 
were only clearly observed in the injured skin sites but were gradually reduced at 7,14 , and 21 days after injection. To verify whether hAMSCs were differentiated into other kinds of cells in vivo, antibody to human-specific nuclei (MAB1281) was used to identify human cells in mouse skin tissues. The immunostaining analysis showed that the MAB1281-positive cells also expressed CD90, suggesting that the human cells present in the skin tissues were still hAMSCs (Fig. 2d). HE staining of wounds on day 7 showed that the number of epidermal and dermal cells significantly increased in hAMSC- and hAMSC-CM-treated mice as compared with PBS- and H-DMEM-treated mice. At 14 days post-injection, HE staining showed that wounds treated with hAMSCs and hAMSC-CM displayed more layers of keratinocytes, indicating enhanced re-epithelialization when compared with PBS- and H-DMEM-treated wounds (Fig. 2e).

In order to test the treatment effect of hAMSCs and hAMSC-CM on apoptosis in the skin tissue, sections from normal, PBS, hAMSCs, H-DMEM, and hAMSCCM groups were subjected to TUNEL staining. After 7 days and 14 days of injection, a significant reduction in cell apoptosis was observed in the hAMSCs and hAMSC-CM group compared to PBS and H-DMEM group, suggesting that hAMSCs and hAMSC-CM inhibited heat stress-induced apoptosis of skin cells in vivo (Fig. 3a). To delineate the pro-proliferative and pro-epithelialization effect of hAMSCs and hAMSC$\mathrm{CM}$ in vivo, immunohistochemistry and western blot were used to detect the expression of PCNA and CK19 in day-7 and day-14 wounds injected with PBS, hAMSCs, or hAMSC-CM. The results showed that hAMSCs and hAMSC-CM significantly increased the expression levels of PCNA and CK19 in the hAMSCand hAMSC-CM-injected skin tissues compared with those in the PBS- and H-DMEM-injected skin tissues (Fig. 3b-e). No significant difference in cell apoptosis and proliferation was observed in the hAMSCs group compared to the hAMSC-CM group. After 7 days and 14 days of injection, CD31 immunofluorescence staining analysis revealed that the numbers of new blood vessels in the hAMSCs and hAMSC-CM group were significantly increased compared to PBS and H-DMEM group (Additional file 2: Figure S2A), indicating that hAMSCs and hAMSC-CM promoted neovascularization in vivo. In vitro, tube formation assay was performed to assess the ability of hAMSC-CM to promote HUVEC angiogenesis. When compared with the control group, there were more tubular structures in the hAMSC-CM at $2 \mathrm{~h}, 4 \mathrm{~h}$, and $6 \mathrm{~h}$ of incubation, which means hAMSC-CM continuously promoted angiogenesis (Additional file 2: Figure S2B and S2C). Taken together, these results indicate that hAMSCs and
hAMSC-CM promote the repair of skin burn injury by enhancing proliferation, angiogenesis, and inhibiting apoptosis of skin cells in the wound area.

\section{hAMSCs and hAMSC-CM inhibited heat stress-induced apoptosis and promoted proliferation of HaCAT and DFL cells in vitro}

To investigate the biological effect of hAMSCs and hAMSC-CM on the apoptosis and proliferation of heat stress-injured skin cells, HaCAT and DFL were treated at $43^{\circ} \mathrm{C}$ for $50 \mathrm{~min}$ and then treated with normal medium (NM), hAMSCs (at a ratio of skin cells to hAMSCs of $1: 1$ ), or $10 \%$ hAMSC-CM (10X). HaCAT and DFL cells not treated at $43{ }^{\circ} \mathrm{C}$ for $50 \mathrm{~min}$ and cultured in a normal medium were used as control. Flow cytometry analysis was performed after $24 \mathrm{~h}$ of treatment. As shown in Fig. 4a, the apoptotic rates of HaCAT and DFL cells co-cultured with hAMSCs or cultured with hAMSC-CM were significantly decreased in comparison to that of the NM group. The apoptotic rates of these HaCAT cells were $36.47 \pm 3.27 \%, 38.92 \pm 2.45 \%$, and $54.59 \pm 4.90 \%$, respectively. The apoptotic rates of DLF cells in the hAMSCs group, hAMSC-CM group, and NM group were $16.54 \pm 2.45 \%, 24.3 \pm 1.63 \%$, and $49.74 \pm 4.08 \%$, respectively (Fig. 4b). Additionally, the apoptotic associated proteins Bcl-2 and Bax in HaCAT and DFL cells were detected by western blot. When compared with NM group, Bcl-2 levels were increased and Bax levels were decreased in the hAMSCs and hAMSC-CM group (Fig. 4c, d).

CCK8 assay showed that the numbers of HaCAT and DFL cells in the hAMSCs and hAMSC-CM groups were sharply increased when compared with the NM group, indicating that significant vitality promotion in HaCAT and DFL cells was induced by hAMSCs and hAMSC$\mathrm{CM}$ at $48 \mathrm{~h}$. In contrast, there was no obvious difference between the hAMSCs group and hAMSC-CM group (Fig. 5a, b). We further studied the expression of proliferation-related proteins in control, heat, hAMSCs, and hAMSC-CM group by using immunofluorescent staining and western blot. As shown in Fig. 5c-f, the expression levels of proliferation-related proteins Ki67 and PCNA in HaCAT and DFL cells of the hAMSCs and hAMSC-CM groups were significantly higher than that in the NM group. These results demonstrated that hAMSCs inhibited heat stress-induced apoptosis in skin cells and promoted their proliferation in a paracrine manner.

\section{hAMSCs and hAMSC-CM promoted heat-injured skin cell migration and wound closure}

To mimic wound healing in vitro and examine whether cytokines secreted from hAMSCs promote cell migration during wound closure, confluent HaCAT and DFL 


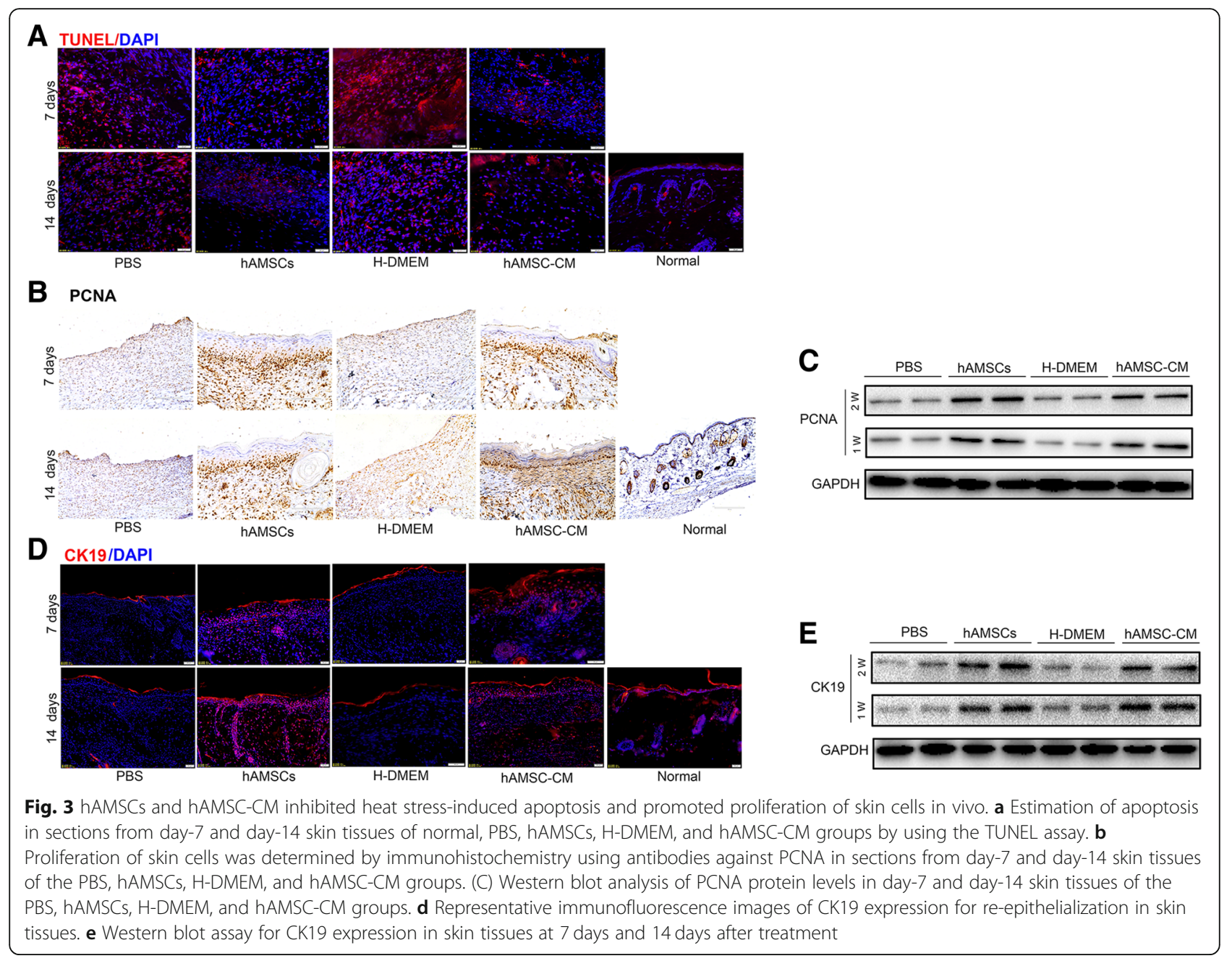

cells were treated at $43{ }^{\circ} \mathrm{C}$ for $50 \mathrm{~min}$ and were scratched to create a linear wound. HaCAT and DFL cells were then cultured with normal medium, hAMSCs, and hAMSC-CM, respectively. The wound margin was marked on the picture, and the wound healing rate was quantified after 2 days of culture. The results showed that higher HaCAT and DFL cell migration was observed in the presence of hAMSCs and hAMSC-CM as compared to the normal medium. At $48 \mathrm{~h}$, the wound closure of HaCAT scratch assays was $83.33 \pm 6.24 \%$ in the hAMSCs group and $84.67 \pm 5.56 \%$ in the hAMSC-CM group, whereas in the NM group, it was $45.0 \pm 5.72 \%$. Similarly, the wound closure of DFL scratch assays was $80.28 \pm 5.76 \%$ in the hAMSCs group, $77 \pm 6.58 \%$ in the hAMSC-CM group, and $38 \pm 4.90 \%$ in the PBS group. However, no significant difference between the hAMSCs group and the hAMSC-CM group was observed (Fig. 6a-d). The scratch wound assay demonstrated that hAMSCs and hAMSC-CM could significantly increase the rate of heat-injured skin cell wound closure compared with a normal medium in vitro.
hAMSCs and hAMSC-CM activate PI3K/AKT/mTOR and GSK3 $\beta / \beta$-catenin pathway in heat-injured skin cells Since we found that hAMSCs and hAMSC-CM inhibited heat stress-induced apoptosis and promoted proliferation of HaCAT and DFL cells in vivo and in vitro, we further investigated its mechanisms. Since PI3K/AKT $[25]$ and GSK3 $\beta / \beta$-catenin $[26,27]$ signaling pathways play important roles in cell survival, cell apoptosis, and skin development, we hypothesized that PI3K/AKT and GSK3 $\beta / \beta$-catenin signaling might be involved in the biological effects of hAMSCs and hAMSC-CM on the heatinjured skin cells. As expected, western blot analysis showed that levels of phospho-PI3K, phospho-AKT, phospho-mTOR, phospho-Gsk $3 \beta$, and $\beta$-catenin were decreased in heat stress-injured HaCAT and DFL cells compared to normal-treated controls. Importantly, this effect was prevented with hAMSCs and hAMSC-CM in both $\mathrm{HaCAT}$ and DFL cells after heat stress injury (Fig. 7a, b). Then to elucidate if the PI3K/AKT signaling pathway is necessary for the hAMSC-mediated apoptosis inhibition, we treated the heat-injured HaCAT and DFL 

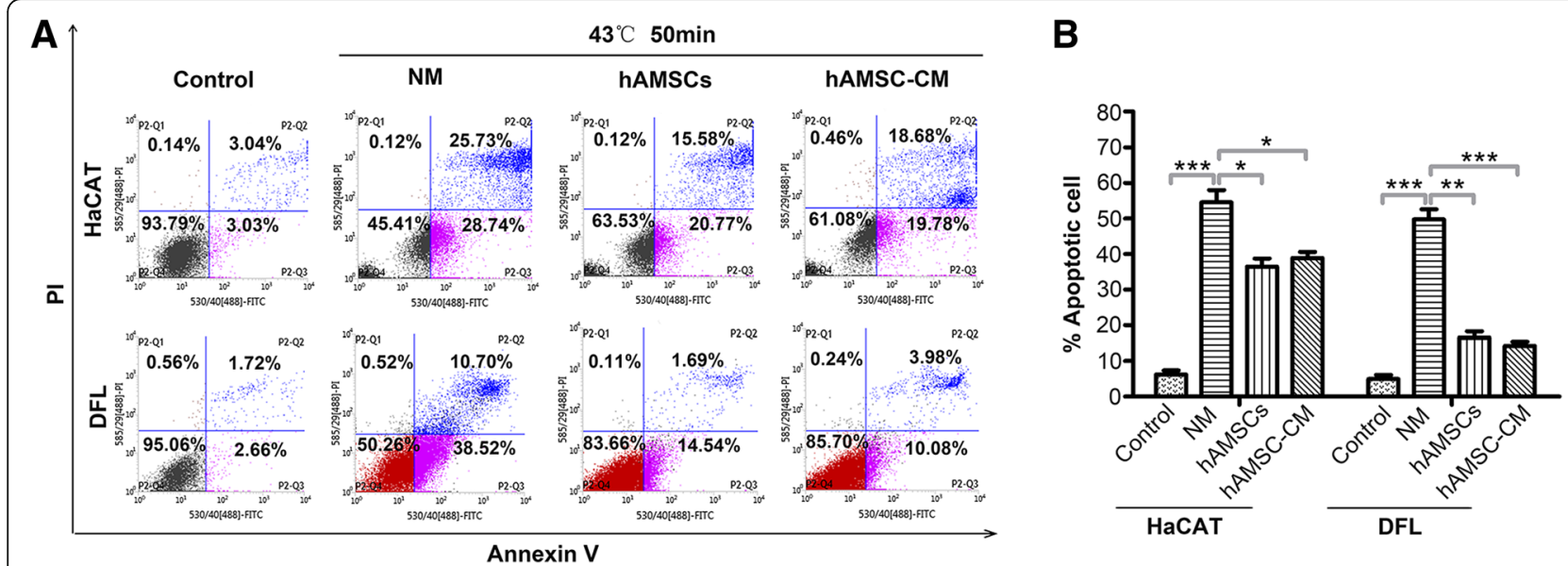

C

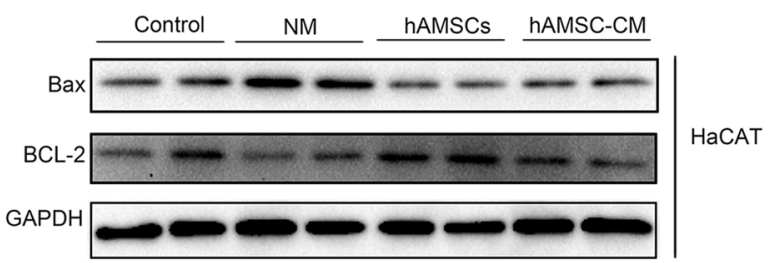

D

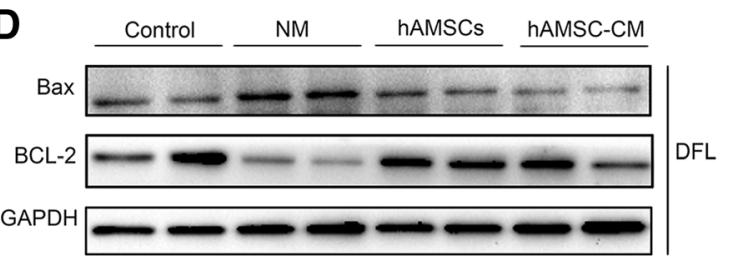

Fig. 4 hAMSCs and hAMSC-CM inhibited heat stress-induced apoptosis of HaCAT and DFL cells. a Examination of apoptosis cells in HaCAT and DFL cells with normal medium (NM), hAMSCs, and hAMSC-CM after $43^{\circ} \mathrm{C} 50$ min heat stress. The apoptosis of cells was assessed by FACS after $24 \mathrm{~h}$ of treatment. b Quantitative analysis of the percentage of apoptotic cells as shown in $\mathbf{a}(n=3)$. c The expression analysis of Bcl-2 and Bax in HaCAT cells of different groups by immunoblotting assay. $\mathbf{d}$ Western blot assay for $\mathrm{Bcl}-2$ and Bax expression in DFL cells of different groups. Significance was measured using a two-way ANOVA. ${ }^{*} P<0.05,{ }^{* *} P<0.01,{ }^{* * *} P<0.001$

cells with hAMSCs with or without PI3K inhibitor, LY294002. We found that hAMSC treatment reduced the numbers of apoptosis cells while the simultaneous treatment with LY294002 reversed this effect. We also treated the heat-injured HaCAT and DFL cells with hAMSCs with or without $\beta$-catenin inhibitor, ICG001. In contrast, we found that inhibition of $\beta$-catenin with ICG001 could not reverse the effects of hAMSCs on the apoptosis inhibition (Fig. 7c-e). Western blot analysis showed that hAMSCs induced the activation of AKT which led to the increase of Bcl-2 protein level and the decline of Bax protein level, which were suppressed by LY294002 (Fig. 7f). These results indicated that hAMSCs reversed acute heat stress-induced apoptosis in HaCAT and DFL cells through activation of PI3K/AKT signaling pathway.

Next, the role of $\beta$-catenin and AKT activation in hAMSC-mediated promotion of cell proliferation was examined. As shown in Fig. 7g, ICG001 significantly inhibited the increase of $\beta$-catenin and PCNA expression by hAMSCs. This result revealed that hAMSCs promoted the proliferation of heat-injured HaCAT and DFL cells by increasing the expression of $\beta$-catenin. Considering that PI3K/AKT and GSK3 $\beta / \beta$-catenin were both activated by hAMSCs, we investigated the relationship between PI3K/AKT and GSK3 $\beta / \beta$-catenin after hAMSC treatment. Inhibition of AKT by LY294002 significantly inhibited the phosphorylation of GSK3 $\beta$ and the increase of $\beta$-catenin and PCNA expression, suggesting that hAMSCs mediate the activation of GSK3 $\beta / \beta$-catenin signaling dependent of PI3K/AKT signaling (Fig. 7h).

\section{A panel of cytokines from hAMSCs might contribute to the acceleration of the thermal burn wound healing} Since hAMSCs co-culture and hAMSC-CM inhibited heat stress-induced apoptosis and promoted proliferation of HaCAT and DFL cells, we therefore hypothesized that the observed anti-apoptosis and pro-proliferation effects were mediated by the paracrine secretion of soluble factors from hAMSCs. To identify the cytokines secreted by hAMSCs that may activate PI3K/AKT signaling, the cytokine profiles of cell supernatants from hAMSCs were analyzed using a RayBiotech Human Cytokine Antibody Array. Among 440 cytokines evaluated (Fig. 8a), some cytokines were not detectably or showed extremely low expression (data not shown). Approximately 200 secreted factors were detected, and the cytokines with an average concentration higher than $200 \mathrm{pg} / \mathrm{ml}$ are shown in Additional file 3: Table S1. Our results showed that hAMSCs expressed high levels of PAI-1 [28], C-GSF [29, 30], periostin [31-33], and TIMP-1 [34], which have been proved to accelerate 


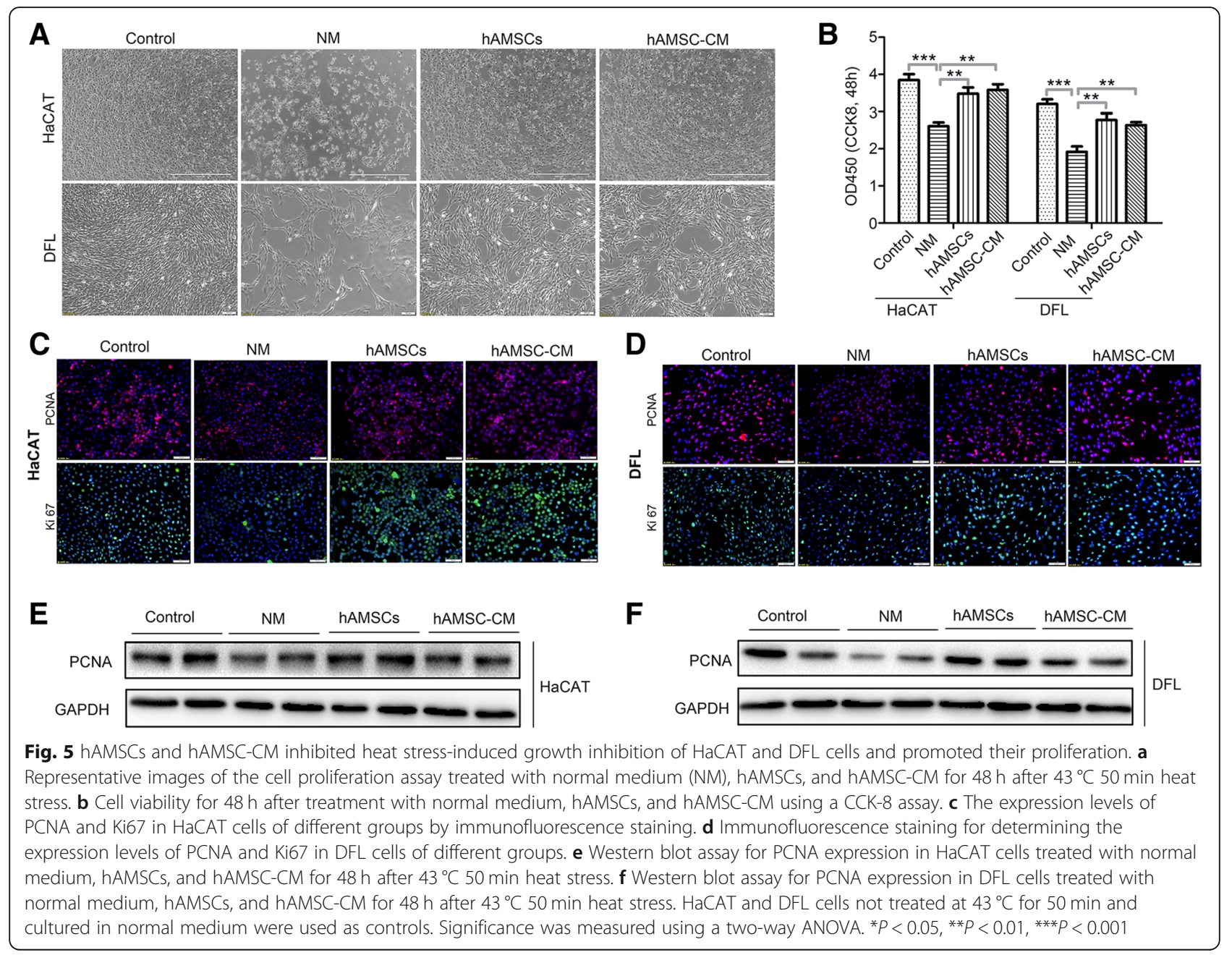

wound healing and increase the anti-apoptotic and proliferative capacity of skin cells by upregulating PI3K/ AKT signaling pathway. The concentration of these cytokines was $47,508.89 \mathrm{pg} / \mathrm{ml}, 23,869.67 \mathrm{pg} / \mathrm{ml}, 22,592.24$ $\mathrm{pg} / \mathrm{ml}$, and $11,697.53 \mathrm{pg} / \mathrm{ml}$, respectively. We also found that uPAR [35-38], IL-6 [39], osteopontin (OPN) [40-42], Angiopoietin-2 (ANG-2) [43], HGF [44-46], TGFb1 [47, 48], RBP4 [49], Angiopoietin-1 (ANG-1) [50-52], FAP [53], IL-11 [54, 55], Follistatin [56], DcR3 [57], Galectin-1 [58], MIF [59, 60], IGF-2 [61, 62], MCP-1 [63], and IL-8 [64, 65] were moderately secreted by hAMSCs, which may activate AKT signaling (Fig. 8a, b).

\section{Discussion}

Stem cells have been considered a promising source of seed cells for biological therapeutics and tissue engineering. However, in terms of clinical applications, the safety, immunological rejection, and ethical criteria are strictly required. The amniotic membrane, a medical waste after birth, has been reported to contain a population of multipotent stem cells exhibiting characteristics of MSCs.
However, less effort has been made on hAMSCs. In the present study, we report that hAMSCs can be easily isolated from the donor's amnion without ethical concerns and showed fibroblast-like morphology. hAMSCs express numerous markers such as the core pluripotency genes (OCT4, SSEA-4, and Nanog) and MSC-specific surface markers (CD29, CD73, CD105, and CD29), but the absence of hematopoietic markers (CD133, CD34, CD45) and HLA Class II (HLA-DR). Our results have also shown that the hAMSCs have low expression of HLA Class I (HLA-ABC) but none of its co-stimulatory molecules CD80, CD86, and CD40, suggesting that there are a weak immunogenicity and potential immune tolerance after transplantation of hAMSCs. In addition, we also found that hAMSCs have multi-lineage differentiation potentials and no tumorigenicity both in vivo and in vitro. These characteristics make hAMSCs as a promising source of stem cells for clinical application.

Several studies showed that MSCs derived from different tissues, such as bone marrow (BM) [14, 20], umbilical cord (UC) [15], and adipose [66], are capable of 

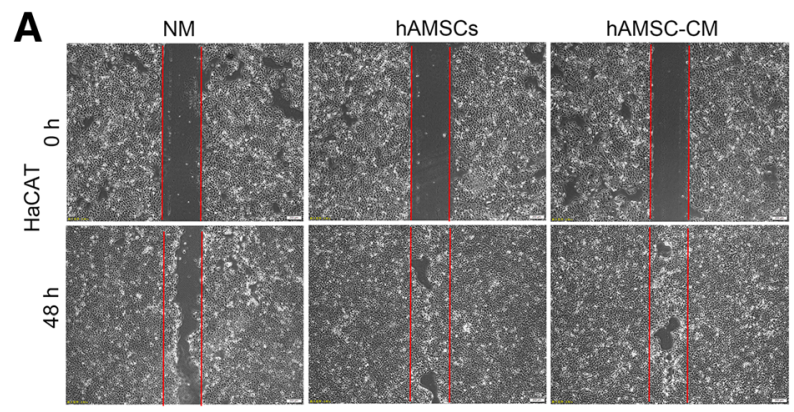

C
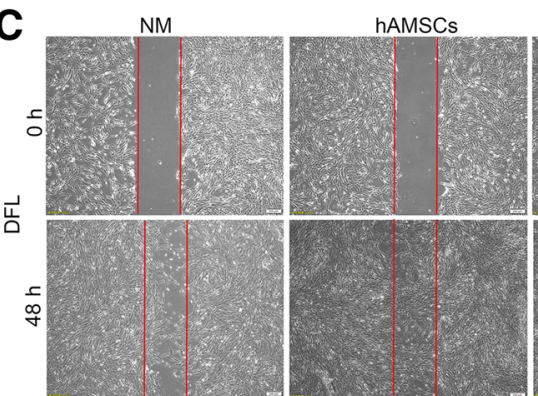

hAMSC-CM

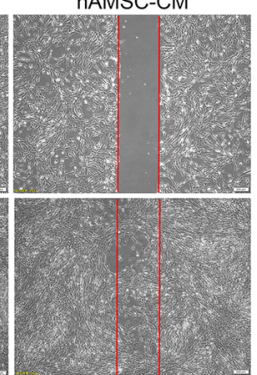

B

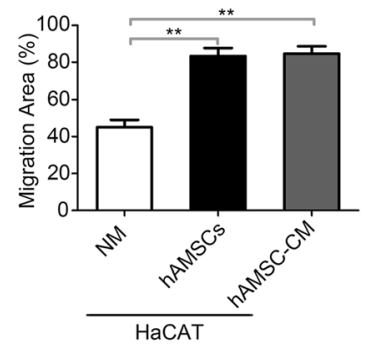

D

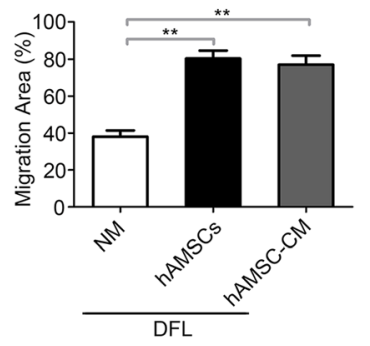

Fig. 6 hAMSCs and hAMSC-CM promoted the migration and wound closure of heat stress-injured HaCAT and DFL cells in a wound scratch assay. Representative images of HaCAT (a) and DFL (c) scratch assays. The images were taken immediately after the scratches had been made and then after $48 \mathrm{~h}$ in the presence of hAMSCs and hAMSC-CM versus normal medium (NM). The red line indicates the initiatory areas without migrating cells. Quantitative analysis of the migration area was performed for HaCAT (b) and DFL (d), respectively. The in vitro wound-healing assay showed that hAMSCs and hAMSC-CM strongly improved the HaCAT and DFL wound closure compared with the NM group. Significance was measured using a two-way ANOVA. ${ }^{*} P<0.05,{ }^{*} P<0.01,{ }^{* * *} P<0.001$

enhancing and improving wound healing in vivo and in vitro. Interestingly, it has been well-documented that the paracrine factors such as growth factors, cytokines, and exosome of stem cells contribute to the therapeutic effect $[67,68]$. Anna et al. demonstrated that UC-derived MSCs enhanced normal skin fibroblast proliferation and migration and promoted wound healing in an excisional full-thickness skin murine model through paracrine signaling [15]. Zhang et al. found that MSC-derived exosome promoted proliferation and inhibited apoptosis of skin cells after heat stress in vitro [17]. In the present study, we reported that hAMSCs and hAMSCs-CM significantly promoted thermal burn wound healing. When the skin on the back of mice is injured with $80^{\circ} \mathrm{C}$ water for $100 \mathrm{~s}$, the skin cells will undergo apoptosis in a short time (within a few days). Our study showed that in vivo transplantation of hAMSCs and hAMSC-CM significantly enhanced re-epithelialization and accelerated wound closure by inhibiting apoptosis and enhancing proliferation of heat-injured skin cells in the wound area in vivo. However, hAMSCs and hAMSC-CM had no significant differences in the wound healing. Therefore, we believe that the critical period of hAMSCs and hAMSC-CM in the treatment of skin scald is the first few days after injury. Thus, despite the limited duration of the action of hAMSC-CM, it still has a similar therapeutic effect as hAMSCs. Although our results showed that hAMSCs could still be found in heat-injured skin wounds 14 and 21 days after cell injection, the numbers of hAMSCs on day 14 or 21 were significantly reduced compared with that of day 7 (Fig. 2c), indicating that the secretion of cytokines might be also significantly reduced and their concentration might be insufficient to significantly promote skin cell proliferation and wound injury repair. Meanwhile, we also demonstrated that hAMSCs and hAMSCs-CM inhibited heat stress-induced apoptosis in skin cells, promoted their proliferation, and increased their migration in a paracrine manner in vitro. To our knowledge, this is the first time to report that hAMSCs and hAMSC-derived factors have the ability to inhibit heat stress-induced apoptosis of HaCAT and DFL cells and promoted proliferation and accelerated wound closure in vitro and in vivo.

The serine/threonine kinase AKT is an important component of the PI3K signaling pathway; active AKT controls many cellular functions, including cell growth, survival, and cell metabolism [69]. Wnt/ $\beta$-catenin signaling plays an important role in embryonic patterning, cell proliferation, differentiation, and angiogenesis [70]. Axin serves as a scaffold protein to recruit GSK3 $\beta$ and CKI $\alpha$ (caspase kinase alpha) along with APC to form a complex with beta-catenin, resulting in beta-catenin phosphorylation, ultimately causing its degradation [71]. The 

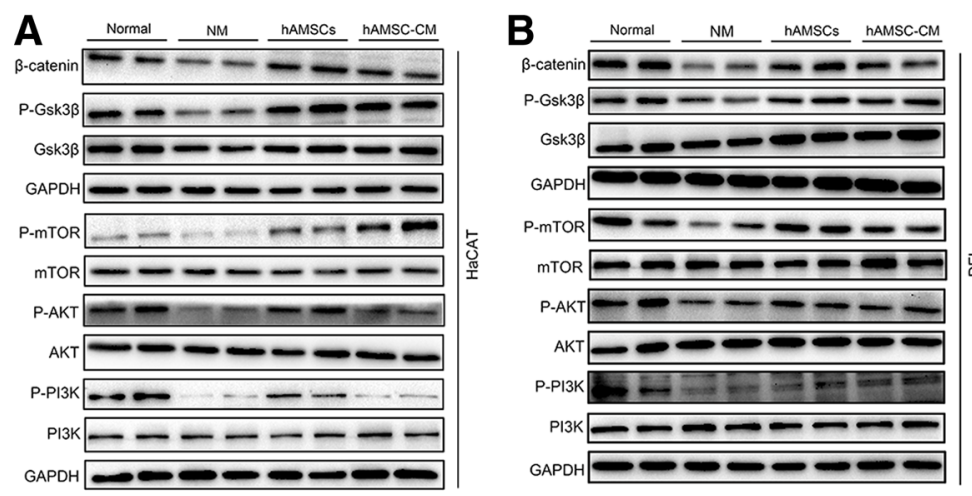

C

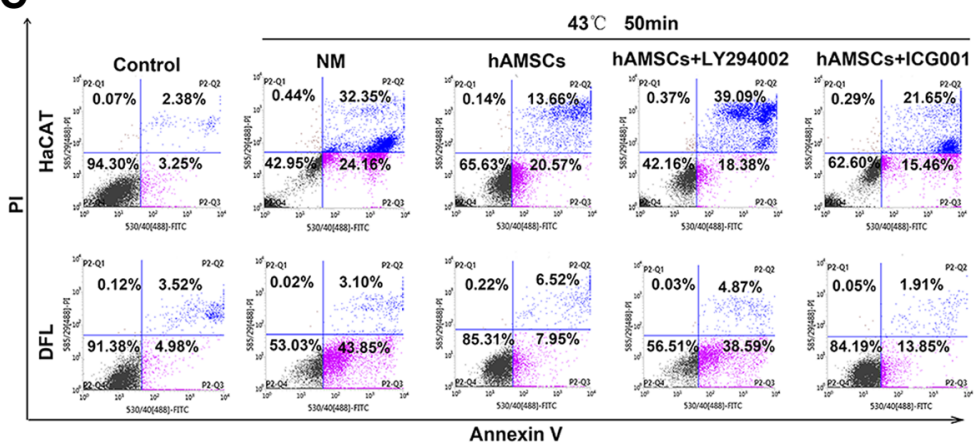

D

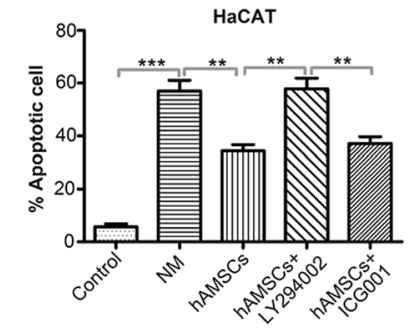

$\mathbf{F}$

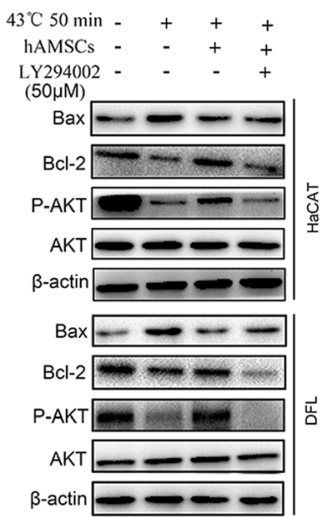

G $(20 \mu \mathrm{M})$
E

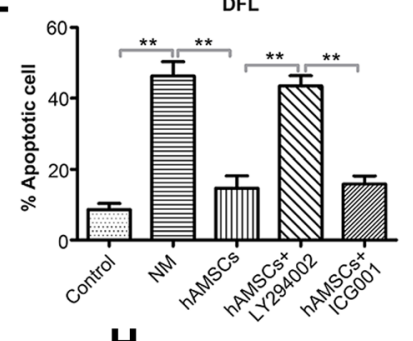

H

$+++$ hAMSCs - $\quad$ - ++

$\mathrm{PCNA} \longrightarrow-$

$\beta$-Catenin $\longrightarrow \ldots$ $\beta$-actin $-\square$

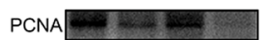
$\beta$-Catenin $=\ldots$ $43^{\circ} \mathrm{C} 50 \mathrm{~min}-\quad+\quad++$ hAMSCs - - + + LY294002 -

PCNA - - - $\beta$-Catenin -P-GSK3B $-\ldots$ GSK3B $\beta$-actin PCNA 岁 $\quad$-Catenin $=-\infty$ P-GSK3B - _ _ _ GSK3B $-\infty$ $\beta$-actin $\longrightarrow$

Fig. 7 (See legend on next page.) 
(See figure on previous page.)

Fig. 7 hAMSCs and hAMSC-CM inhibited heat stress-induced apoptosis and promoted proliferation of heat-injured HaCAT and DFL cells by activating PI3K/AKT signaling. The phospho-PI3K, phospho-AKT, phospho-mTOR, phospho-Gsk3 $\beta$, and $\beta$-catenin were determined by western blot analysis in heat-injured HaCAT (a) and DFL (b) cells. The downregulations of the phosphorylation of the protein were prevented by hAMSCs and hAMSC-CM. c Apoptosis analysis of HaCAT and DFL cells. The cells were subjected to heat stress $\left(43^{\circ} \mathrm{C}, 50 \mathrm{~min}\right)$ and treated with normal medium (NM), hAMSCs, or hAMSCs with LY294002 $(50 \mu \mathrm{M})$ or ICG001 $(20 \mu \mathrm{M})$. The apoptosis of cells was assessed by FACS after $24 \mathrm{~h}$ of treatment, and the percentage of apoptotic HaCAT (d) and DFL (e) cells was quantitatively analyzed as shown in $\mathbf{c}(n=3)$. f Western blot assay for Bax, Bcl-2, P-AKT, and AKT in heat-injured HaCAT and DFL cells treated with hAMSCs in the presence or absence of LY294002 (50 $\mu \mathrm{M})$. $\mathbf{g}$ Western blot assay for $\beta$ catenin and PCNA in heat-injured HaCAT and DFL cells treated with hAMSCs in the presence or absence of ICG001 (20 $\mu \mathrm{M})$. $\mathbf{h}$ Western blot assay for Gsk3ß, P- Gsk3ß, $\beta$-catenin, and PCNA in heat-injured HaCAT and DFL cells treated with hAMSCs in the presence or absence of LY294002 $(50 \mu \mathrm{M})$. HaCAT and DFL cells not treated at $43^{\circ} \mathrm{C}$ for $50 \mathrm{~min}$ and cultured in a normal medium were used as controls. Significance was measured using a two-way ANOVA. ${ }^{*} P<0.05,{ }^{*} P<0.01,{ }^{* *} P<0.001$

phosphorylation of GSK3 $\beta$ is a classic negative regulator of Wnt signaling pathway. Many investigators have described that PI3K/AKT and GSK3 $\beta / \beta$-catenin signaling play a key role in skin development and cutaneous wound healing $[26,33,72]$. Our results show that hAMSCs and hAMSC-CM significantly reversed heat stress-induced decline of phosphorylation of PI3K, AKT, GSK3 $\beta$, and $\beta$ catenin expression levels in HaCAT and DFL cells, indicating that activations of PI3K/AKT and GSK3 $\beta / \beta$-catenin signaling pathways might be involved in the therapeutic effects of hAMSCs and hAMSC-CM on the heat-injured wound healing in skin cells. Furthermore, we demonstrated that hAMSC- or hAMSC-CM-mediated activation of GSK3 $\beta / \beta$-catenin signaling was dependent on PI3K/
AKT signaling since the inhibition of hAMSCs or CM on apoptosis could be reversed by PI3K inhibitor LY294002, but not $\beta$-catenin inhibitor ICG001 although ICG001 significantly inhibited the hAMSC-mediated increase of PCNA expression. All of these results indicated that hAMSCs and hAMSC-CM reversed acute thermal injuryinduced apoptosis and growth inhibition in skin cells through activation of PI3K/AKT signaling pathway.

To identify the hAMSC-secreted molecules involved in the activation of PI3K/AKT pathway, the cytokines of hAMSC-CM were analyzed using an antibody array. Our results showed that hAMSC-CM contained high levels of PAI-1, C-GSF, periostin, and TIMP-1. PAI-1 is the most abundant factor in the hAMSC-CM. Harman et al. found
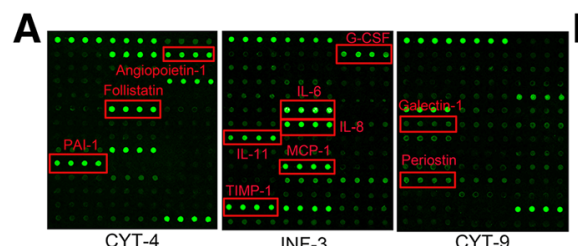

B
\begin{tabular}{|c|c|c|c|} 
cytokines & $\begin{array}{c}\text { hAMSCs-1 } \\
\text { (pg/ml) }\end{array}$ & $\begin{array}{c}\text { hAMSCs-2 } \\
\text { (pg/ml) }\end{array}$ & $\begin{array}{c}\text { hAMSCs-3 } \\
\text { (pg/ml) }\end{array}$ \\
\hline PAI-1 & 49649.16 & 43180.31 & 49697.21 \\
\hline G-CSF & 9104.90 & 99.05 & 62404.46 \\
\hline Periostin & 20352.08 & 31005.20 & 16419.45 \\
\hline TIMP-1 & 20210.60 & 13651.51 & 11230.50 \\
\hline UPAR & 4041.60 & 4444.59 & 3340.53 \\
\hline IL-6 & 4072.01 & 4143.62 & 3549.92 \\
\hline OPN & 3533.10 & 3432.30 & 3740.95 \\
\hline ANG-2 & 3207.08 & 2075.61 & 2263.71 \\
\hline HGF & 2438.37 & 2386.27 & 2319.56 \\
\hline TGFbl & 969.04 & 1197.46 & 484.16 \\
\hline RBP4 & 1940.54 & 1796.08 & 1856.57 \\
\hline ANG-1 & 2083.74 & 969.65 & 2076.57 \\
\hline FAP & 2313.26 & 1347.69 & 939.11 \\
\hline IL-1l & 1239.83 & 1265.63 & 1387.20 \\
\hline Follistatin & 1401.97 & 1140.71 & 1348.72 \\
\hline DcR3 & 1189.01 & 987.74 & 943.83 \\
\hline Galectin-1 & 817.06 & 1128.52 & 548.10 \\
\hline MIF & 970.60 & 507.90 & 515.14 \\
\hline IGF-2 & 812.45 & 522.99 & 470.75 \\
\hline MCP-1 & 551.51 & 621.38 & 613.17 \\
\hline IL-8 & 251.48 & 263.22 & 256.60 \\
\hline & & & \\
\hline
\end{tabular}

Fig. 8 Cytokine expression profile of hAMSCs. The cytokine expression profile in the conditioned media collected from hAMSCs was detected using the RayBio Human Cytokine Antibody Array 440, which allows the detection of 440 cytokines in one experiment. a The representative image of cytokine antibody array. The cytokines in the hAMSC-CM which may activate PI3KJAKT signaling are highlighted with red boxes. $\mathbf{b}$ The concentration of cytokines of interest in each hAMSC-CM sample is shown. Values shown are obtained from standard curve generated against the various proteins, $n=4$ 
that MSC-derived PAI-1 significantly increased DFL migration in vitro and improved wound healing in vivo by decreasing time to wound closure [73]. Lademann et al. found PAI-1 protects fibrosarcoma cells from etoposideinduced apoptosis through activation of PI3K/AKT cell survival pathway [28]. G-CSF, a hematopoietic cytokine and potent stem cell mobilization agent, has been proved to accelerate wound healing by enhancing angiogenesis and attenuating apoptosis [30], and PI3K/AKT signaling pathway would be activated in response to G-CSF stimulation [29]. Periostin, one of the matricellular proteins, is normally expressed in adult skin, which is highly upregulated during wound healing [31]. Periostin has the ability to activate the PI3K/AKT signaling pathway in tumor cells by interacting with integrin molecules [74]. Recently, increasing evidence suggested that periostin is capable of dramatically increasing the migratory and proliferative abilities of epithelial cells and dermal fibroblasts by upregulating AKT/mTOR signaling pathway [32, 33]. Tissue inhibitor of metalloproteinases-1 (TIMP-1) possesses actions of promoting growth and anti-apoptosis in cells. It has been reported that TIMP- 1 reduced cell apoptosis during the process of wound healing [34]. In addition, other cytokines such as uPAR, IL-6, OPN, ANG-2, HGF, TGFb1, RBP4, ANG-1, FAP, IL-11, Follistatin, DcR3, Galectin-1, MIF, IGF-2, MCP-1, and IL-8 were moderately secreted by hAMSCs, and the cytokines have been identified to have the ability to activate PI3K/AKT pathway. However, although the acceleration of hAMSCs and hAMSC-CM on skin wound healing may be involved in activating PI3K/AKT pathway, it is hard to determine which cytokine(s) in hAMSC-CM mediate the activation of PI3K/AKT pathway due to the complexity of hAMSCCM components.

\section{Conclusion}

In the present study, we demonstrated that hAMSCs and hAMSC-CM accelerate skin wound healing in vivo and inhibit acute heat stress-induced skin cells apoptosis and promoted their proliferation in vitro via activation of PI3K/AKT pathway. Antibody Array assay showed that PAI-1, C-GSF, periostin, TIMP-1, and uPAR secreted by hAMSCs might be involved in the activation of PI3K/ AKT signaling pathway. Our findings suggest that the administration of hAMSCs or hAMSC-CM may be a novel therapeutic strategy for skin injury repair clinically.

\section{Additional files}

Additional file 1: Figure S1. Tumorogenesis of hAMSCs in vivo and in vitro. (A) hAMSCs and HepG2 cells were grown in soft agar, and the colony formation was analyzed after 30 days of cell growth. (B) $5 \times 10^{6}$ hAMSCs cells were injected into the right back and left thigh muscle of NOD-SCID mice for observation of teratoma formation. There was no any tumor formation after 5 months of hAMSC injections. Embryonic stem cells were used as a positive control. (TIF $8547 \mathrm{~kb}$ )

Additional file 2: Figure S2. hAMSCs and hAMSC-CM enhanced neovascularization in vivo and induce HUVECs angiogenesis in vitro. (A) Representative immunofluorescence images of CD31 expression in the wound area after treatment with PBS, hAMSCs, H-DMEM, and hAMSC-CM for 7 days and 14 days. Normal skin was used as a control. (B) Enhanced tube formation in HUVECs treated with hAMSC-CM at different time point. (TIF $5037 \mathrm{~kb}$ )

Additional file 3: Table S1. Antibody array assay for determining secretions of the cytokines from hAMSCs. (DOCX $16 \mathrm{~kb}$ )

\section{Abbreviations}

ANG: Angiopoietin; BM: Bone marrow; CM: Conditioned medium; DFL: Dermal fibroblasts; FACS: Fluorescence-activated cell sorting; hAESCs: Human amniotic epithelial stem cells; hAMSCs: Human amniotic mesenchymal stem cells; H-DMEM: High-glucose Dulbecco's modified Eagle's medium; HRP: Horseradish peroxidase; MSCs: Mesenchymal stem cells; NM: Normal medium; OPN: Osteopontin; PE: Phycoerythrin; PI: Propidium iodide; RT-PCR: Reverse transcription-polymerase chain reaction; UC: Umbilical cord

\section{Acknowledgements}

The authors thank the healthy donors from the First Affiliated Hospital of Nanchang University for kindly providing placenta. We also extend special thanks to the Laboratory Animal Center of Institute of Translational Medicine, Nanchang University.

\section{Authors' contributions}

HBX and QWL contributed to the conception and design of the study, collection and/or assembly of data, data analysis and interpretation, and manuscript writing. JYL performed the in vivo and in vitro experiments. KKR participated in the hAMSC isolation and characterization by flow cytometry. WJZ performed animal experiments and were responsible for animal handling. LX, HYW, QYL, TD, WJN, YK, and KYD contributed to the experimentation. XCZ provided some of the study materials. All authors read and approved the final version of the manuscript.

\section{Funding}

This work was supported by the National Natural Science Foundation of China (81760118 to QWL, 81760140 to KYD, 81873659 and 91639106 to HBX); Jiangxi Provincial Department of Science and Technology, China (2018ACB21043 to QWL); Jiangxi provincial Department of Education

(GJJ150214 to QWL); the grant for Jiangxi Provincial Collaborative Innovation Center of Biopharmaceutics and Biotechnology (2015202004 to HBX); and the grants from the Science Foundation of Nanchang University (06301204 to QWL).

\section{Availability of data and materials}

The data that support the findings of this study are available from the corresponding author upon reasonable request.

\section{Ethics approval and consent to participate}

All procedures involving animals were approved by the Institutional Animal Care and Use Committees at Nanchang University and conducted in accordance with the national guidelines on animal care.

\section{Consent for publication}

Not applicable.

\section{Competing interests}

The authors declare that they have no competing interests.

\section{Author details}

${ }^{1}$ The National Engineering Research Center for Bioengineering Drugs and the Technologies, Institute of Translational Medicine, Nanchang University, No. 1299 Xuefu Road, Honggutan District, Nanchang 330031, People's Republic of China. ${ }^{2}$ School of Life and Science, Nanchang University, Nanchang 330031, People's Republic of China. ${ }^{3}$ Department of Obstetrics 
and Gynecology, The First Affiliated Hospital of Nanchang University, Nanchang 330006, People's Republic of China.

\section{Received: 14 May 2019 Revised: 29 July 2019} Accepted: 30 July 2019 Published online: 09 August 2019

\section{References}

1. Nourian Dehkordi A, Mirahmadi Babaheydari F, Chehelgerdi M, Raeisi DS. Skin tissue engineering: wound healing based on stem-cell-based therapeutic strategies. Stem Cell Res Ther. 2019;10(1):111.

2. Lee DE, Ayoub N, Agrawal DK. Mesenchymal stem cells and cutaneous wound healing: novel methods to increase cell delivery and therapeutic efficacy. Stem Cell Res Ther. 2016;7:37.

3. Chen JS, Wong WW, Gurtner GC. Therapeutic potential of bone marrowderived mesenchymal stem cells for cutaneous wound healing. Front Immunol. 2012;3:192

4. Watt SM, Pleat JM. Stem cells, niches and scaffolds: applications to burns and wound care. Adv Drug Deliv Rev. 2018;123:82-106.

5. Rowan MP, Cancio LC, Elster EA, et al. Burn wound healing and treatment: review and advancements. Crit Care. 2015;19:243.

6. Rodgers K, Jadhav SS. The application of mesenchymal stem cells to treat thermal and radiation burns. Adv Drug Deliv Rev. 2018;123:75-81.

7. Liu L, Yu Y, Hou Y, et al. Human umbilical cord mesenchymal stem cells transplantation promotes cutaneous wound healing of severe burned rats. PLoS One. 2014;9(2):e88348.

8. Liang $X$, Ding $Y$, Zhang $Y$, Tse HF, Lian Q. Paracrine mechanisms of mesenchymal stem cell-based therapy: current status and perspectives. Cell Transplant. 2014;23(9):1045-59.

9. Walter MN, Wright KT, Fuller HR, MacNeil S, Johnson WE. Mesenchymal stem cell-conditioned medium accelerates skin wound healing: an in vitro study of fibroblast and keratinocyte scratch assays. Exp Cell Res. 2010;316(7): 1271-81.

10. Maharlooei MK, Bagheri M, Solhjou Z, et al. Adipose tissue derived mesenchymal stem cell (AD-MSC) promotes skin wound healing in diabetic rats. Diabetes Res Clin Pract. 2011;93(2):228-34.

11. Nie C, Yang D, Xu J, Si Z, Jin X, Zhang J. Locally administered adiposederived stem cells accelerate wound healing through differentiation and vasculogenesis. Cell Transplant. 2011;20(2):205-16.

12. Rodriguez-Menocal L, Shareef S, Salgado M, Shabbir A, Van Badiavas E. Role of whole bone marrow, whole bone marrow cultured cells, and mesenchymal stem cells in chronic wound healing. Stem Cell Res Ther. 2015;6:24.

13. Zhang QZ, Su WR, Shi SH, et al. Human gingiva-derived mesenchymal stem cells elicit polarization of $\mathrm{m} 2$ macrophages and enhance cutaneous wound healing. Stem Cells. 2010;28(10):1856-68

14. Qi Y, Jiang D, Sindrilaru A, et al. TSG-6 released from intradermally injected mesenchymal stem cells accelerates wound healing and reduces tissue fibrosis in murine full-thickness skin wounds. J Invest Dermatol. 2014;134(2): 526-37

15. Arno Al, Amini-Nik S, Blit PH, et al. Human Wharton's jelly mesenchymal stem cells promote skin wound healing through paracrine signaling. Stem Cell Res Ther. 2014;5(1):28.

16. Yang Z, He C, He J, Chu J, Liu H, Deng X. Curcumin-mediated bone marrow mesenchymal stem cell sheets create a favorable immune microenvironment for adult full-thickness cutaneous wound healing. Stem Cell Res Ther. 2018;9(1):21.

17. Zhang B, Wang M, Gong A, et al. HucMSC-exosome mediated-Wnt4 signaling is required for cutaneous wound healing. Stem Cells. 2015;33(7): 2158-68.

18. Hu C, Yong X, Li C, et al. CXCL12/CXCR4 axis promotes mesenchymal stem cell mobilization to burn wounds and contributes to wound repair. J Surg Res. 2013;183(1):427-34.

19. Hosni Ahmed H, Rashed LA, Mahfouz S, et al. Can mesenchymal stem cells pretreated with platelet-rich plasma modulate tissue remodeling in a rat with burned skin? Biochem Cell Biol. 2017;95(5):537-48

20. Oh EJ, Lee HW, Kalimuthu S, et al. In vivo migration of mesenchymal stem cells to burn injury sites and their therapeutic effects in a living mouse model. J Control Release. 2018;279:79-88.

21. Liu QW, Liu QY, Li JY, et al. Therapeutic efficiency of human amniotic epithelial stem cell-derived functional hepatocyte-like cells in mice with acute hepatic failure. Stem Cell Res Ther. 2018;9(1):321.
22. Arno A, Smith AH, Blit PH, Shehab MA, Gauglitz GG, Jeschke MG. Stem cell therapy: a new treatment for burns? Pharmaceuticals (Basel). 2011;4(10): 1355-80.

23. Ponec M, Weerheim A, Kempenaar J, et al. The formation of competent barrier lipids in reconstructed human epidermis requires the presence of vitamin C. J Invest Dermatol. 1997;109(3):348-55.

24. Zellmer S, Reissig D. Isolation, cultivation, and differentiation of normal human epidermal keratinocytes in serum-free medium. Methods Mol Biol. 2002:188:179-84.

25. Whittaker $S$, Marais $R$, Zhu AX. The role of signaling pathways in the development and treatment of hepatocellular carcinoma. Oncogene. 2010; 29(36):4989-5005

26. Bielefeld KA, Amini-Nik S, Alman BA. Cutaneous wound healing: recruiting developmental pathways for regeneration. Cell Mol Life Sci. 2013;70(12):2059-81.

27. Huelsken J, Vogel R, Erdmann B, Cotsarelis G, Birchmeier W. Beta-catenin controls hair follicle morphogenesis and stem cell differentiation in the skin. Cell. 2001:105(4):533-45.

28. Romer MU, Larsen L, Offenberg H, Brunner N, Lademann UA. Plasminogen activator inhibitor 1 protects fibrosarcoma cells from etoposide-induced apoptosis through activation of the PI3K/Akt cell survival pathway. Neoplasia. 2008:10(10):1083-91.

29. Tsai RK, Chang CH, Sheu MM, Huang ZL. Anti-apoptotic effects of human granulocyte colony-stimulating factor (G-CSF) on retinal ganglion cells after optic nerve crush are PI3K AKT-dependent. Exp Eye Res. 2010;90(5):537-45.

30. Huang H, Zhang Q, Liu J, Hao H, Jiang C, Han W. Granulocyte-colony stimulating factor (G-CSF) accelerates wound healing in hemorrhagic shock rats by enhancing angiogenesis and attenuating apoptosis. Med Sci Monit. 2017:23:2644-53.

31. Elliott CG, Wang J, Guo X, et al. Periostin modulates myofibroblast differentiation during full-thickness cutaneous wound repair. J Cell Sci. 2012; 125(Pt 1):121-32.

32. Ontsuka $\mathrm{K}$, Kotobuki $Y$, Shiraishi $\mathrm{H}$, et al. Periostin, a matricellular protein, accelerates cutaneous wound repair by activating dermal fibroblasts. Exp Dermatol. 2012;21(5):331-6.

33. Castilho RM, Squarize $\mathrm{CH}$, Gutkind JS. Exploiting PI3K/mTOR signaling to accelerate epithelial wound healing. Oral Dis. 2013;19(6):551-8.

34. Lao G, Ren M, Wang $X$, et al. Human tissue inhibitor of metalloproteinases-1 improved wound healing in diabetes through its anti-apoptotic effect. Exp Dermatol. 2017

35. Liu Y, Pan YF, Xue YQ, et al. UPAR promotes tumor-like biologic behaviors of fibroblast-like synoviocytes through PI3K/Akt signaling pathway in patients with rheumatoid arthritis. Cell Mol Immunol. 2018;15(2):171-81.

36. Nowicki TS, Zhao H, Darzynkiewicz Z, et al. Downregulation of UPAR inhibits migration, invasion, proliferation, FAK/PI3K/Akt signaling and induces senescence in papillary thyroid carcinoma cells. Cell Cycle. 2011;10(1):100-7.

37. Malla R, Gopinath S, Alapati K, et al. Downregulation of UPAR and cathepsin $\mathrm{B}$ induces apoptosis via regulation of $\mathrm{BCl}-2$ and $\mathrm{Bax}$ and inhibition of the PI3K/Akt pathway in gliomas. PLoS One. 2010;5(10):e13731.

38. Gondi CS, Kandhukuri N, Dinh DH, Gujrati M, Rao JS. Down-regulation of UPAR and UPA activates caspase-mediated apoptosis and inhibits the PI3K AKT pathway. Int J Oncol. 2007;31(1):19-27.

39. Wei L, Xiong H, Li W, Li B, Cheng Y. Upregulation of IL-6 expression in human salivary gland cell line by IL-17 via activation of p38 MAPK, ERK, PI3K/Akt, and NF-kappaB pathways. J Oral Pathol Med. 2018;47(9):847-55.

40. Liang J, Xu L, Zhou F, et al. MALAT1/miR-127-5p regulates osteopontin (OPN)-mediated proliferation of human chondrocytes through PI3K/Akt pathway. J Cell Biochem. 2018;119(1):431-9.

41. Zhang W, Cui Y, Gao J, et al. Recombinant osteopontin improves neurological functional recovery and protects against apoptosis via PI3K Akt/GSK-3beta pathway following intracerebral hemorrhage. Med Sci Monit. 2018:24:1588-96.

42. Xu J, Yi Y, Li L, Zhang W, Wang J. Osteopontin induces vascular endothelial growth factor expression in articular cartilage through PI3KJAKT and ERK1/2 signaling. Mol Med Rep. 2015;12(3):4708-12.

43. Gao H, Chen P, Wei L, et al. Angiopoietin-1 and angiopoietin-2 protect porcine iliac endothelial cells from human antibody-mediated complementdependent cytotoxicity through phosphatidylinositide 3-kinase/AKT pathway activation. Xenotransplantation. 2017;24(4):e12309.

44. Yang S, Guo Y, Zhang W, Zhang J, Zhang Y, Xu P. Effect of FGF-21 on implant bone defects through hepatocyte growth factor (HGF)-mediated PI3K/AKT signaling pathway. Biomed Pharmacother. 2019;109:1259-67. 
45. Ding $X, X i$ W, Ji J, et al. HGF derived from cancer associated fibroblasts promotes vascularization in gastric cancer via PI3K/AKT and ERK1/2 signaling. Oncol Rep. 2018;40(2):1185-95.

46. Deying W, Feng G, Shumei L, Hui Z, Ming L, Hongqing W. CAF-derived HGF promotes cell proliferation and drug resistance by up-regulating the c-Met/ PI3K/Akt and GRP78 signalling in ovarian cancer cells. Biosci Rep. 2017;37(2): BSR20160470.

47. Choi JH, Hwang YP, Kim HG, et al. Saponins from the roots of Platycodon grandiflorum suppresses TGFbeta1-induced epithelial-mesenchymal transition via repression of PI3K/Akt, ERK1/2 and Smad2/3 pathway in human lung carcinoma A549 cells. Nutr Cancer. 2014;66(1):140-51.

48. Lien SC, Usami S, Chien S, Chiu JJ. Phosphatidylinositol 3-kinase/Akt pathway is involved in transforming growth factor-beta1-induced phenotypic modulation of 10T1/2 cells to smooth muscle cells. Cell Signal. 2006;18(8):1270-8

49. Li H, Cao G, Zhang N, et al. RBP4 regulates trophoblastic cell proliferation and invasion via the PI3KJAKT signaling pathway. Mol Med Rep. 2018;18(3): 2873-9.

50. Yin D, Li C, Kao RL, et al. Angiopoietin-1 inhibits doxorubicin-induced human umbilical vein endothelial cell death by modulating fas expression and via the PI3K/Akt pathway. Endothelium. 2004;11(5-6):247-52.

51. Liu XB, Jiang J, Gui C, Hu XY, Xiang MX, Wang JA. Angiopoietin-1 protects mesenchymal stem cells against serum deprivation and hypoxia-induced apoptosis through the PI3K/Akt pathway. Acta Pharmacol Sin. 2008;29(7):815-22.

52. Parborell F, Abramovich D, Irusta G, Tesone M. Angiopoietin 1 reduces rat follicular atresia mediated by apoptosis through the PI3K/Akt pathway. Mol Cell Endocrinol. 2011;343(1-2):79-87.

53. Wang $H$, Wu Q, Liu Z, et al. Downregulation of FAP suppresses cell proliferation and metastasis through PTEN/PI3K AKT and Ras-ERK signaling in oral squamous cell carcinoma. Cell Death Dis. 2014;5:e1155.

54. Zhong Z, Hu Z, Jiang Y, et al. Interleukin-11 promotes epithelial-mesenchymal transition in anaplastic thyroid carcinoma cells through PI3K/Akt/GSK3beta signaling pathway activation. Oncotarget. 2016;7(37):59652-63.

55. Yang $L$, Wang $R$, Gao $Y$, et al. The protective role of interleukin-11 against neutron radiation injury in mouse intestines via MEK/ERK and PI3K/Akt dependent pathways. Dig Dis Sci. 2014;59(7):1406-14.

56. Li $\mathrm{X}$, Liu $\mathrm{H}$, Wang $\mathrm{H}$, et al. Follistatin could promote the proliferation of duck primary myoblasts by activating PI3K/Akt/mTOR signalling. Biosci Rep. 2014;34(5):e00143.

57. Ge H, Liang C, Li Z, et al. DcR3 induces proliferation, migration, invasion, and EMT in gastric cancer cells via the PI3K/AKT/GSK-3beta/beta-catenin signaling pathway. Onco Targets Ther. 2018;11:4177-87.

58. Zhang PF, Li KS, Shen YH, et al. Galectin-1 induces hepatocellular carcinoma EMT and sorafenib resistance by activating FAK/PI3K/AKT signaling. Cell Death Dis. 2016;7:e2201.

59. Lue H, Thiele M, Franz J, et al. Macrophage migration inhibitory factor (MIF) promotes cell survival by activation of the Akt pathway and role for CSN5/JAB1 in the control of autocrine MIF activity. Oncogene. 2007;26(35):5046-59.

60. Zhang W, Zheng J, Meng J, Neng L, Chen X, Qin Z. Macrophage migration inhibitory factor mediates viability and apoptosis of PVM/Ms through PI3K Akt pathway. Neuroscience. 2017;360:220-9.

61. Ji $Y$, Wang $Z$, Li Z, et al. Silencing IGF-II impairs C-myc and $\mathrm{N}$-ras expressions of SMMC-7721 cells via suppressing FAK/PI3K/Akt signaling pathway. Cytokine. 2017:90:44-53.

62. Codina M, Garcia de la serrana D, Sanchez-Gurmaches J, et al. Metabolic and mitogenic effects of IGF-II in rainbow trout (Oncorhynchus mykiss) myocytes in culture and the role of IGF-II in the PI3K/Akt and MAPK signalling pathways. Gen Comp Endocrinol. 2008;157(2):116-24.

63. Chang M, Guo F, Zhou Z, et al. HBP induces the expression of monocyte chemoattractant protein-1 via the FAK/PI3K/AKT and p38 MAPK/NF-kappaB pathways in vascular endothelial cells. Cell Signal. 2018;43:85-94.

64. Shao N, Lu Z, Zhang Y, et al. Interleukin-8 upregulates integrin beta3 expression and promotes estrogen receptor-negative breast cancer cell invasion by activating the PI3K/Akt/NF-kappaB pathway. Cancer Lett. 2015; 364(2):165-72.

65. Yang A, Lu Y, Xing J, et al. IL-8 enhances therapeutic effects of BMSCs on bone regeneration via CXCR2-mediated PI3K/Akt signaling pathway. Cell Physiol Biochem. 2018;48(1):361-70.

66. Wu LW, Chen WL, Huang SM, Chan JY. Platelet-derived growth factor-AA is a substantial factor in the ability of adipose-derived stem cells and endothelial progenitor cells to enhance wound healing. FASEB J. 2018;33(2): 2388-95.

67. ELA S, Mager I, Breakefield XO, Wood MJ. Extracellular vesicles: biology and emerging therapeutic opportunities. Nat Rev Drug Discov. 2013; 12(5):347-57.

68. Ren S, Chen J, Duscher D, et al. Microvesicles from human adipose stem cells promote wound healing by optimizing cellular functions via AKT and ERK signaling pathways. Stem Cell Res Ther. 2019;10(1):47.

69. Andjelkovic M, Alessi DR, Meier R, et al. Role of translocation in the activation and function of protein kinase B. J Biol Chem. 1997;272(50): 31515-24.

70. Khalaf AM, Fuentes D, Morshid Al, et al. Role of Wnt/beta-catenin signaling in hepatocellular carcinoma, pathogenesis, and clinical significance. J Hepatocell Carcinoma. 2018;5:61-73.

71. Krishnamurthy N, Kurzrock R. Targeting the Wnt/beta-catenin pathway in cancer: update on effectors and inhibitors. Cancer Treat Rev. 2018;62:50-60.

72. Takeo M, Lee $\mathbf{W}$, Ito M. Wound healing and skin regeneration. Cold Spring Harb Perspect Med. 2015;5(1):a023267.

73. Harman RM, He MK, Zhang S, GR VANDEW. Plasminogen activator inhibitor1 and tenascin- $C$ secreted by equine mesenchymal stromal cells stimulate dermal fibroblast migration in vitro and contribute to wound healing in vivo. Cytotherapy. 2018;20(8):1061-76.

74. Gillan L, Matei D, Fishman DA, Gerbin CS, Karlan BY, Chang DD. Periostin secreted by epithelial ovarian carcinoma is a ligand for alpha(V)beta(3) and alpha(V)beta(5) integrins and promotes cell motility. Cancer Res. 2002;62(18): 5358-64.

\section{Publisher's Note}

Springer Nature remains neutral with regard to jurisdictional claims in published maps and institutional affiliations.

Ready to submit your research? Choose BMC and benefit from:

- fast, convenient online submission

- thorough peer review by experienced researchers in your field

- rapid publication on acceptance

- support for research data, including large and complex data types

- gold Open Access which fosters wider collaboration and increased citations

- maximum visibility for your research: over $100 \mathrm{M}$ website views per year

At BMC, research is always in progress.

Learn more biomedcentral.com/submissions 